\title{
Growth of cyclone Viyaru and Phailin - a comparative study
}

\author{
S D Kotal ${ }^{1}$, S K Bhattacharya ${ }^{1, *}$, S K Roy Bhowmik ${ }^{1}$ and P K Kundu ${ }^{2}$ \\ ${ }^{1}$ India Meteorological Department, NWP Division, New Delhi 110 003, India. \\ ${ }^{2}$ Department of Mathematics, Jadavpur University, Kolkata 700 032, India. \\ *Corresponding author.e-mail: sumit.kumar.bhattacharya@gmail.com
}

The tropical cyclone Viyaru maintained a unique quasi-uniform intensity during its life span. Despite being in contact with sea surface for $>120 \mathrm{hr}$ travelling about $2150 \mathrm{~km}$, the cyclonic storm (CS) intensity, once attained, did not intensify further, hitherto not exhibited by any other system over the Bay of Bengal. On the contrary, the cyclone Phailin over the Bay of Bengal intensified into very severe cyclonic storm (VSCS) within about $48 \mathrm{hr}$ from its formation as depression. The system also experienced rapid intensification phase (intensity increased by $30 \mathrm{kts}$ or more during subsequent 24 hours) during its life time and maximum intensity reached up to $115 \mathrm{kts}$. In this paper, a comparative study is carried out to explore the evolution of the various thermodynamical parameters and possible reasons for such converse features of the two cyclones. Analysis of thermodynamical parameters shows that the development of the lower tropospheric and upper tropospheric potential vorticity (PV) was low and quasi-static during the lifecycle of the cyclone Viyaru. For the cyclone Phailin, there was continuous development of the lower tropospheric and upper tropospheric PV, which attained a very high value during its lifecycle. Also there was poor and fluctuating diabatic heating in the middle and upper troposphere and cooling in the lower troposphere for Viyaru. On the contrary, the diabatic heating was positive from lower to upper troposphere with continuous development and increase up to $6^{\circ} \mathrm{C}$ in the upper troposphere. The analyses of cross sections of diabatic heating, PV, and the 1000-500 hPa geopotential metre (gpm) thickness contours indicate that the cyclone Viyaru was vertically tilted (westward) and lacked axisymmetry in its structure and converse features (axisymmetric and vertical) that occurred for the cyclone Phailin. In addition, there was a penetration of dry air in the middle troposphere of Viyaru, whereas high moisture existed in the middle troposphere of Phailin. The vertical wind shear $\left(5-10 \mathrm{~ms}^{-1}\right)$ near the core of the storm region between 850 and $200 \mathrm{hPa}$ was favourable for both the systems but was higher in the northern region of the cyclone Viyaru. The divergent development of these thermodynamic features conspired to produce converse characteristic of the two cyclones.

\section{Introduction}

Operational forecasting of tropical cyclones primarily involves genesis, track, and intensity predictions before and after landfall. A major hurdle for the study of the structure of tropical cyclones had been lack of data over the seas. During the last few decades efforts have been made to tackle these challenges. Assimilation of enormous satellite data into the sophisticated numerical weather prediction (NWP) models has enabled the researchers to look into the intricacies of the structure by studying different important variables at various levels of the atmosphere within and around the systems.

Keywords. Cyclogenesis; diabatic heating; potential vorticity; vertical wind shear. 
Several studies have been carried out in forecasting tropical cyclone. A tropical cyclone genesis parameter was defined by Gray (1968) as a product of three thermodynamic parameters, viz., sea surface temperature (SST) $\left(>26^{\circ} \mathrm{C}\right.$ up to a depth of $60 \mathrm{~m}$ ), mid-tropospheric relative humidity, and three dynamical parameters, viz., Coriolis parameter, reciprocal of vertical wind shear, and relative vorticity in the lower levels of the troposphere. DeMaria et al. (2001), McBride and Zehr (1981) developed different methods to predict cyclogenesis using various dynamical and thermodynamical atmospheric variables. Roy Bhowmik (2003) highlighted some threshold values of Genesis parameter to differentiate the degree of intensification at early genesis stages over the Indian seas. Kotal et al. (2009) developed a Genesis Potential Parameter (GPP) consisting of various dynamical and thermodynamical variables to differentiate between nondeveloping and developing low pressure systems over the North Indian Ocean.

Sanders and Gyakum (1980) defined 'bomb' as an extratropical surface cyclone with central pressure falling at the rate of $1 \mathrm{mb} \mathrm{h}^{-1}$ or more for 24 hours. Most of the studies on rapid cyclogenesis and rapid decay have been carried out for systems over the Atlantic Ocean and Pacific Ocean (Anthes et al. 1983; Sanders 1986; Kuo and Reed 1988; Whitaker et al. 1988; Kuo et al. 1991; Bosart et al. 1995; Kaplan and DeMaria 2003; Martin and Otkin 2004; Kaplan et al. 2009). Kotal et al. (2012) carried out a case study of rapid intensification of cyclone GIRI over the Bay of Bengal. They found the lower-tropospheric latent heat release and the resulting increase of positive lower PV anomaly by the effect of this latent heat release played a major role for rapid intensification of the cyclone. Recently, Kotal and Roy Bhowmik (2013) developed a statistical-dynamical technique for probabilistic forecast of rapid intensification of cyclone.

The average life span of tropical cyclones over the North Indian Ocean is $4-5$ days out of which 3-4 days are spent over the seas prior to landfall. Best track data of IMD during the period May 1990 to May 2013 show that only nine tropical cyclones spent their journey, a period of 120 hr or more, over the sea surface, from the stage of depression. Out of which, eight subsequently crossed coasts and one decayed over the seas without making landfall. Barring cyclone Viyaru, all the eight cyclones attained a maximum intensity equal to or more than severe cyclonic strom (SCS) intensity ( $>47$ kts). The cyclone Viyaru maintained cyclone intensity (34-47 kts) for $126 \mathrm{hr}$ travelling about 2150 $\mathrm{km}$, neither decayed nor intensified. Whereas, the cyclone Phailin over the Bay of Bengal intensified into very severe cyclonic storm (VSCS) within about $48 \mathrm{hr}$ from its formation as depression. The system also experienced rapid intensification phase (intensity increased by 30 kts or more during subsequent $24 \mathrm{hr}$ ) during its life time and maximum intensity reached up to $115 \mathrm{kts}$. An insight into different aspects of both the systems is necessary to understand the mechanism of the growth of the system to cyclonic storm and maintenance of the quasi-uniform intensity for an unusually long duration for cyclone Viyaru and rapid intensification of the cyclone Phailin. Therefore, this study includes analyses of dynamical and thermodynamical parameters to explain the converse feature of the cyclone Viyaru and Phailin.

The paper is organized as follows: brief lifecycle of the cyclone Viyaru and Phailin is described in section 2. The data sample used in this study is described in section 3. A synoptic overview of the environmental condition is given in section 4 . Analyses of thermodynamic features are presented in section 5. Summary and conclusions are given in section 6 .

\section{Cyclonic storms}

\subsection{Cyclonic storm Viyaru (10-16 May 2013)}

A low pressure system that formed over southeast Bay of Bengal on 8 May 2013 intensified into depression at 0900 UTC of 10 May 2013 near lat. $5.0^{\circ} \mathrm{N}$ and long. $92.0^{\circ} \mathrm{E}$. Initially it moved northwestwards and intensified into a deep depression at 1200 UTC of the same day and further intensified into a cyclonic storm (T.No. 2.5), Viyaru at 0300 UTC of 11 May 2013. The cyclonic storm recurved to north-northeasterly direction on 13 and 14 May and further intensified from T.No. 2.5 to T.No. 3.0 at 0600 UTC of 16 May 2013. Moving northnortheastward direction the cyclonic storm crossed Bangladesh coast near lat. $22.8^{\circ} \mathrm{N}$ and long. $91.4^{\circ} \mathrm{E}$, around 0800 UTC of 16 May 2013. After landfall, it continued to move north-northeastwards and weakened into a deep depression over Mizoram at 1200 UTC and into a depression over Manipur at 1800 UTC of 16 May 2013. It further weakened into a well marked low pressure area over Nagaland at 0000 UTC 17 May 2013. The observed track of the cyclone Viyaru is shown in figure 1.

\subsection{Very severe cyclonic storm Phailin (8-14 October 2013)}

A low pressure system that formed over North Andaman Sea on 7 October 2013 intensified into depression at 0300 UTC of 8 October 2013 near lat. $12.0^{\circ} \mathrm{N}$ and long. $96.0^{\circ} \mathrm{E}$. It moved northwestwards and intensified into a deep depression at 


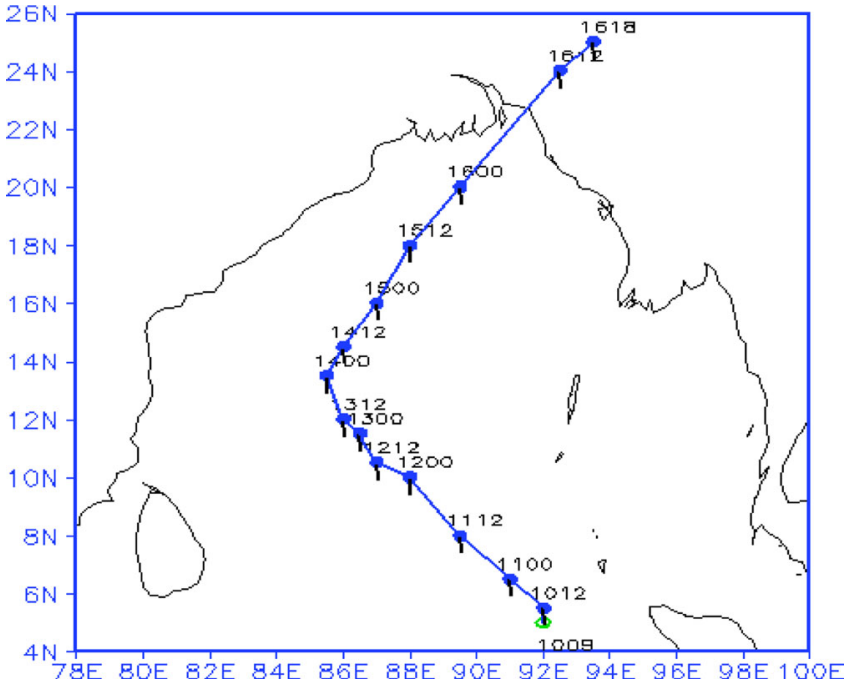

Figure 1. Observed track of the cyclone Viyaru.

0000 UTC of 9 October 2013 and further intensified into a cyclonic storm (T.No. 2.5), Phailin at 1200 UTC of the same day. The cyclonic storm continued to move in northwesterly direction and intensified into severe cyclonic storm (T.No. 3.5) at 0300 UTC of 10 October 2013 and subsequently intensified into very severe cyclonic storm (T.No. 4.0) at 0600 UTC of same day. Moving northwestward direction the system further rapidly intensified to T.No. 4.5, T.No. 5.0, and T.No. 5.5 at 1200, 1500, and 2100 UTC of same day (10 October 2013), respectively. At 0300 UTC of 11 October 2013 the system intensified to T.No. 6.0 and continued to move northwesterly direction with same intensity towards Odisha and crossed coast near Gopalpur at around 1700 UTC of 12 October 2013. The system maintained its intensity of VSCS up to $7 \mathrm{hr}$ after landfall and cyclonic storm intensity till 1200 UTC of 13 October 2013. The system continued to decay and weakened to deep depression at 1800 UTC of 13 October 2013 and further to depression at 0300 UTC of 14 October 2013. The observed track of the cyclone Phailin is shown in figure 2.

\section{Data sources}

The observed data for the cyclone Viyaru and Phailin, viz., track positions, intensity, and other variables have been taken from the database of the cyclone division of the Regional Specialized Meteorological Centre (RSMC), IMD, New Delhi. World Meteorological Organization (WMO) recognizes this office as the RSMC for providing cyclone warning advisories for the North Indian Ocean. The mesoscale forecast system Weather Research and Forecast WRFDA (version 3.2) with 3DVAR data assimilation is being operated to generate mesoscale analysis at $27 \mathrm{~km}$ and $9 \mathrm{~km}$

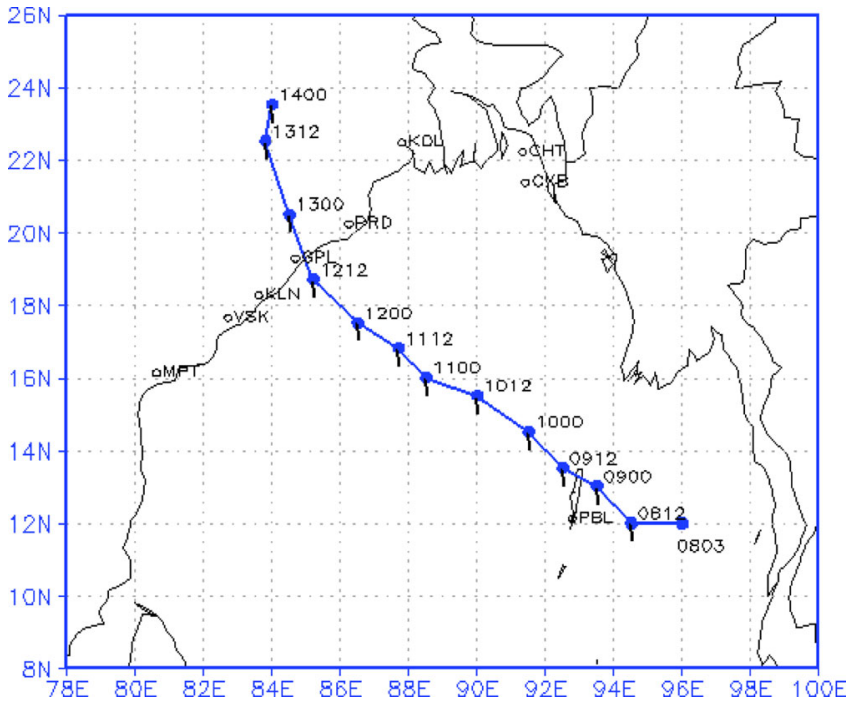

Figure 2. Observed track of the cyclone Phailin.

horizontal resolutions using IMD GFS-T574L64 analysis as first guess and forecasts as boundary conditions. Using analysis and boundary conditions from the WRFDA, the WRF (ARW) is run for the forecast up to 3 days with double nested configuration with horizontal resolution of $27 \mathrm{~km}$ and $9 \mathrm{~km}$ and 38 Eta levels in the vertical. WRF at resolution $9 \mathrm{~km}$ data have been used for the analyses of various thermodynamic parameters for the study of growth of tropical cyclone intensity for Viyaru and Phailin. The nonintensification of cyclone Viyaru is cross-validated with JTWC (Joint Typhoon Warning Center) track data and satellite imagery (Kalpana-I). JTWC track observation data also shows nonintensification of the cyclone Viyaru with maximum intensity 50 kts and quasi-static, whereas Regional Specialized Meteorological Centre (RSMC), New Delhi data shows maximum intensity $45 \mathrm{kts}$ during its life period (figure 3). Satellite imagery of Kalpana-I shows convection was less for cyclone Viyaru during its life period compared to cyclone Phailin.

\section{Synoptic overview and analysis of thermodynamic parameters}

\subsection{Sea level pressure (SLP) and 1000-500 hPa thickness (gpm)}

Analysis of SLP for cyclone Viyaru at 0000 UTC of 12 June 2013 (figure 4a) shows that the lowest central SLP was $1002 \mathrm{hPa}$. The contours of the geopotential thickness $(1000-500 \mathrm{hPa})$ were distributed towards east of the centre of the system (marked ' $\mathrm{C}$ ' in figure 4a). At 0000 UTC of 13 June 2013, the central SLP (figure 4b) decreased to 1000 $\mathrm{hPa}$. The contours of the gpm (geopotential meter) 


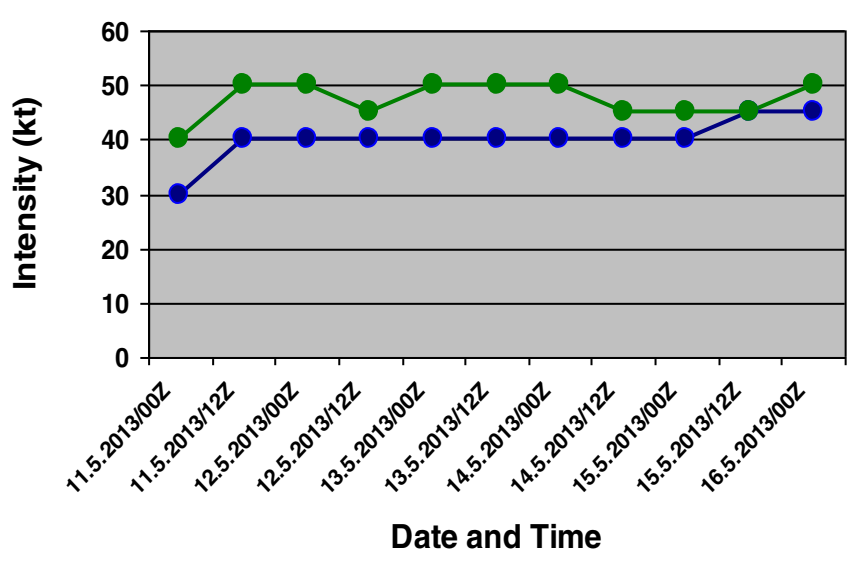

$\rightarrow-I M D \rightarrow-J T W C$

Figure 3. Estimated intensity of Viyaru (maximum sustained surface wind) (a) IMD (blue) and (b) JTWC (green).

thickness were located towards east of the system centre (figure $4 \mathrm{~b}$ ) with no change of gpm thickness during previous 24 hours. At 0000 UTC of 14 June 2013, the central SLP (figure 4c) decreased to 998 $\mathrm{hPa}$. The contour centre of the gpm thickness was located towards east of the system centre (marked 'C'), and increased by about $10 \mathrm{gpm}$ in previous 24 hours. At 0000 UTC of 15 June 2013, minimum SLP decreased to $996 \mathrm{hPa}$ and the contour centre of the gpm thickness was further shifted towards southeast of the centre of the system (figure 4d) and the thickness increased by about 10 gpm near the centre.

Analysis of SLP for cyclone Phailin at 0000 UTC of 9 October 2013 (figure 5a) shows that the lowest central SLP was $1002 \mathrm{hPa}$. The contour centre of the geopotential thickness was located towards northeast of the centre of the system (marked ' $\mathbf{C}$ ' in figure 5a). At 0000 UTC of 10 October 2013, the central SLP (figure 5b) decreased to $1000 \mathrm{hPa}$. The contours of the gpm thickness were distributed slightly towards northeast of the system centre (figure 5b) with an increase of thickness (15 gpm) during previous 24 hours. At 0000 UTC of 11 October 2013, the central SLP (figure 5c) decreased to $996 \mathrm{hPa}$. The contours of the gpm thickness and SLP centre became concentric (marked 'C'), and gpm thickness increased by about $10 \mathrm{gpm}$ in previous 24 hours. At 0000 UTC of 12 October 2013, minimum SLP further decreased to $992 \mathrm{hPa}$ (figure 5d) and the contours of the gpm thickness and the centre of the system (figure 5d) persisted as concentric and the thickness increased by $10 \mathrm{gpm}$ near the centre.

\subsection{East-west vertical cross section of diabatic heating}

Figure 6(a-d) shows the vertical cross section of the diabatic heating for cyclone Viyaru. The

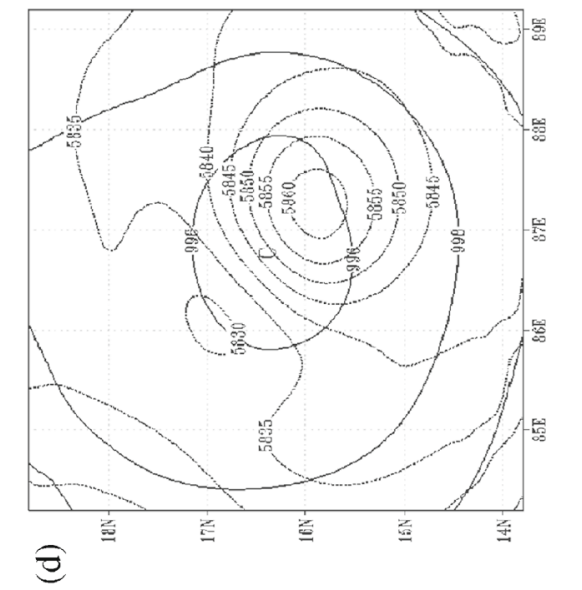

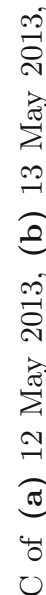
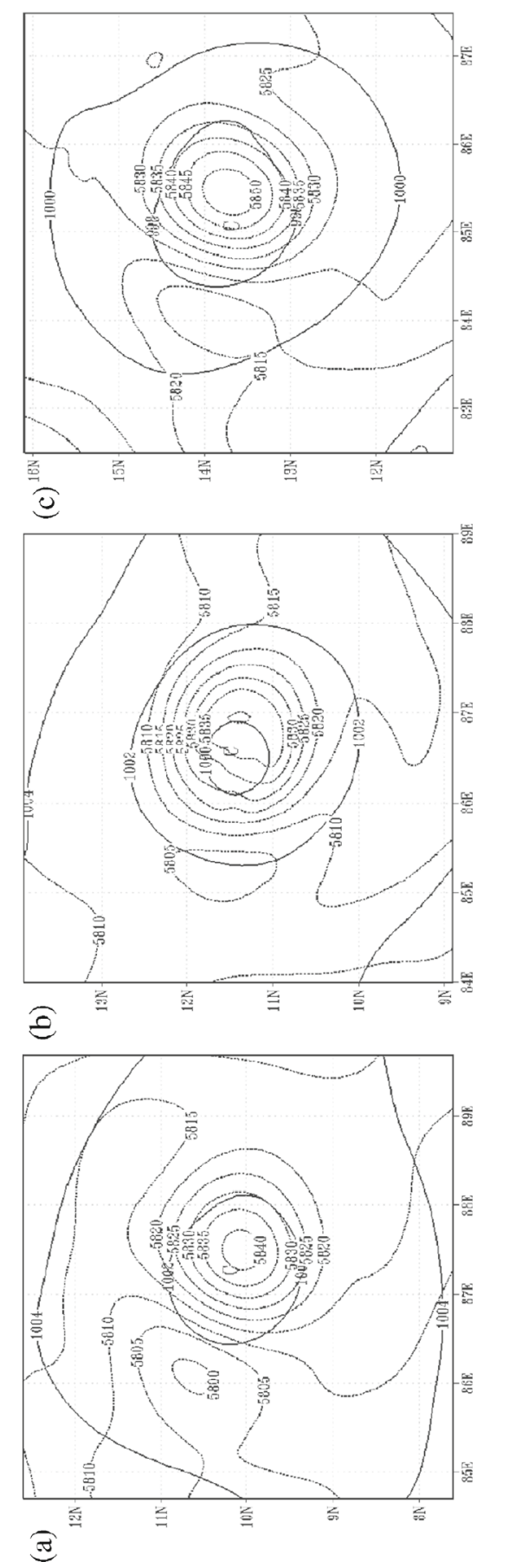

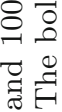

产

굴 

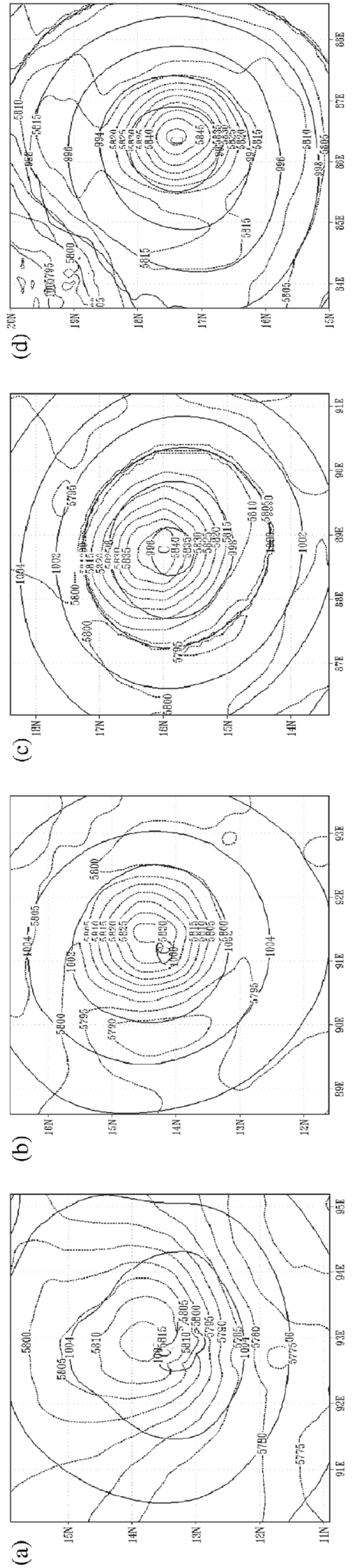
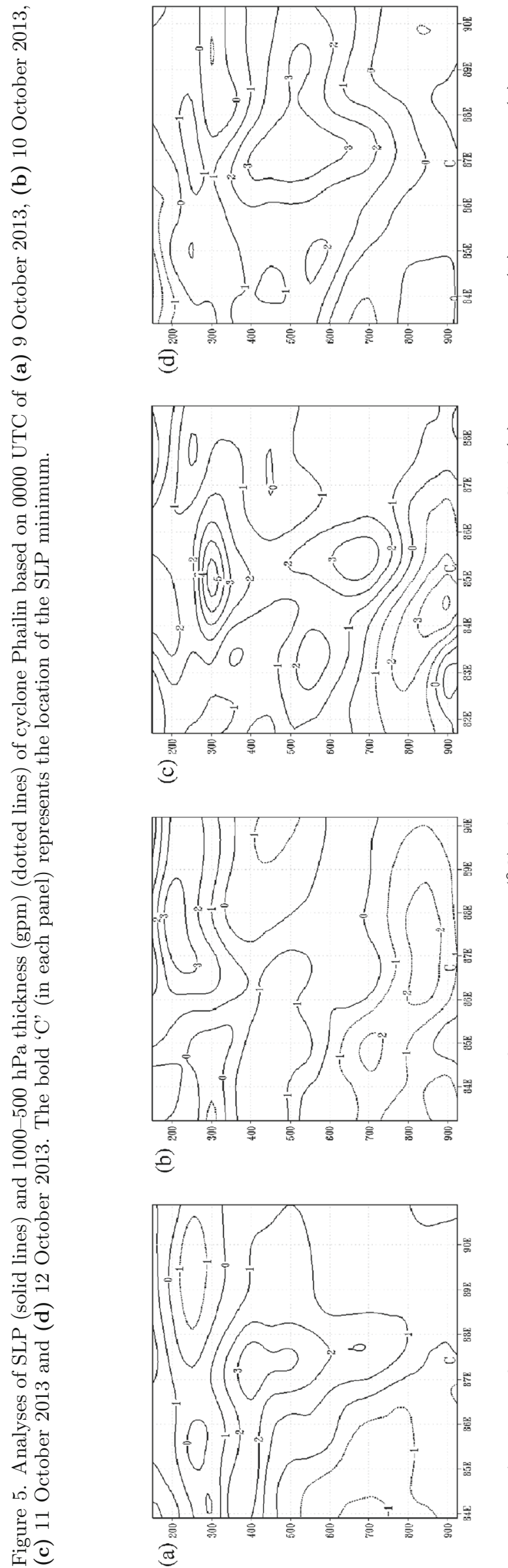

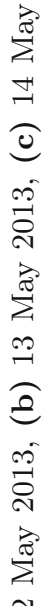

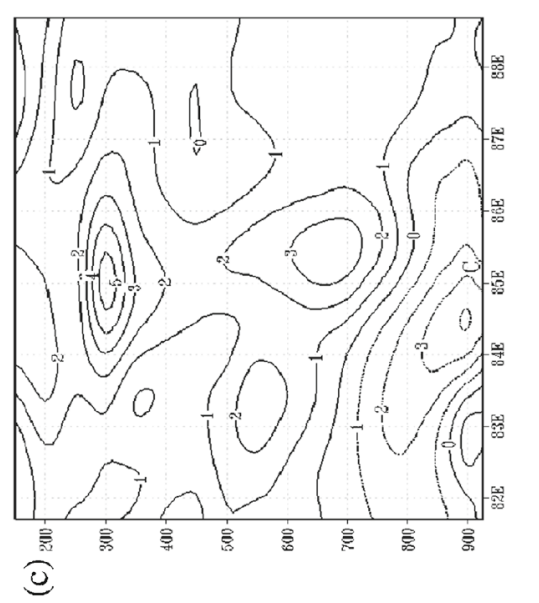

త్ర

U

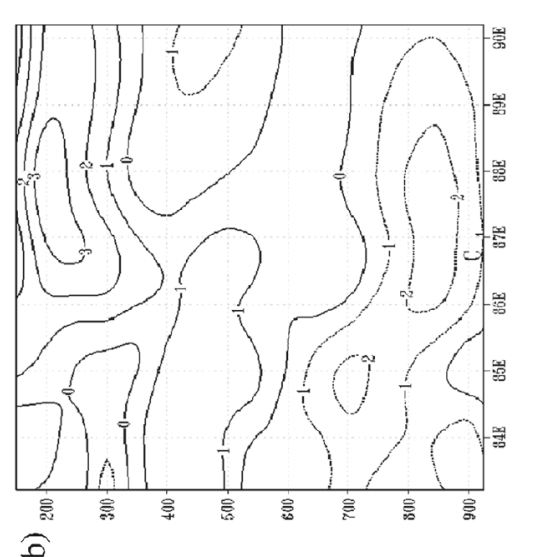

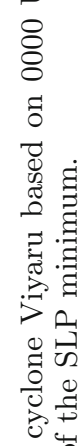

पै।

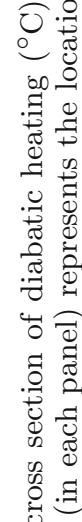

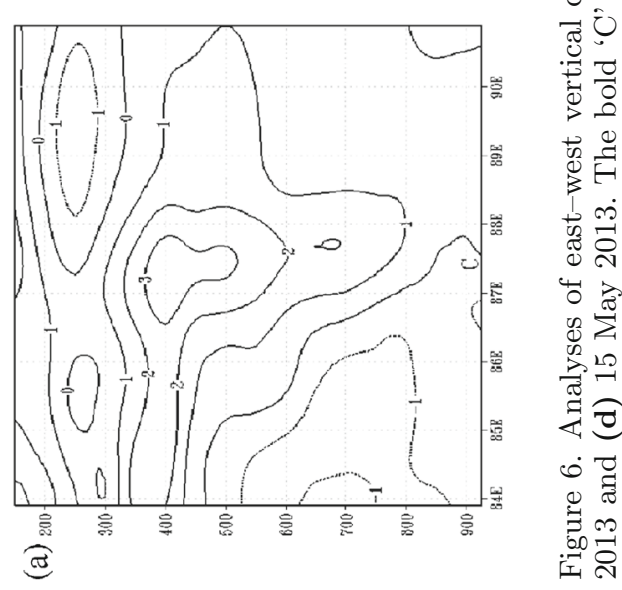


figure shows that between 0000 UTC of 11 May 2013 and 0000 UTC of 13 May 2013, there was a rise in temperature in the upper troposphere, $1^{\circ}-5^{\circ} \mathrm{C}$ between 400 and $150 \mathrm{hPa}$ level (figure $6 \mathrm{a}-\mathrm{c}$ ) and slightly west of the system centre (marked 'C'). The diabatic heating in the upper troposphere decreased thereafter from $5^{\circ}$ to $1^{\circ} \mathrm{C}$ (figure 6d). In the middle troposphere, the diabatic heating decreased from $3^{\circ} \mathrm{C}$ to $1^{\circ} \mathrm{C}$ during 12-13 May 2013 and increased to $3^{\circ} \mathrm{C}$ on 14 May 2013 (figure 6a-d). In the lower troposphere, diabatic heating decreased from $1^{\circ}$ to $-3^{\circ} \mathrm{C}$ during 11-13 May 2013 and became zero on 14 May 2013 (figure $6 \mathrm{a}-\mathrm{d}$ ).

For cyclone Phailin, the diabatic heating increased in the middle and upper troposphere (figure $7 \mathrm{a}-\mathrm{d}$ ) during its life period. In the upper troposphere, the diabatic heating increased from $2^{\circ}$ to $6^{\circ} \mathrm{C}$ and in the middle troposphere, the diabatic heating increased from $2^{\circ}$ to $3^{\circ} \mathrm{C}$. The diabatic heating increased by $1^{\circ} \mathrm{C}$ in each 24-hr period during the life period of Phailin in the lower troposphere. The significant feature for cyclone Phailin is that the core of the diabatic heating was above the cyclone centre at all vertical levels at all stages (figure $7 \mathrm{a}-\mathrm{d}$ ).

\subsection{Potential vorticity}

Figure $8(\mathrm{a}-\mathrm{d})$ shows that the lower troposphere $(925-700 \mathrm{hPa})$ potential vorticity $(\mathrm{PV})$ for cyclone Viyaru increased from $3 \times 10^{-6}$ to $4 \times 10^{-6} \mathrm{~m}^{2}$ $\mathrm{K} \mathrm{kg}^{-1} \mathrm{~s}^{-1}$ during 12-13 May 2013 and maintained same value during subsequent 24 hours and decreased thereafter. The centre of PV also gradually displaced towards southeast of the cyclone centre (marked 'C') from 12-15 May 2013. Figure $9(\mathrm{a}-\mathrm{d})$ shows that the lower troposphere (925-700 hPa) potential vorticity (PV) for cyclone Phailin increased from $2 \times 10^{-6}$ to $7 \times 10^{-6} \mathrm{~m}^{2} \mathrm{~K} \mathrm{~kg}^{-1}$ $\mathrm{s}^{-1}$ during 9-12 October 2013. The centre of PV and the cyclone centre (marked ' $\mathbf{C}$ ') was nearly concentric.

The upper troposphere $(400-250 \mathrm{hPa}) \mathrm{PV}$ around the system for cyclone Viyaru increased from $1 \times 10^{-6}$ to $2 \times 10^{-6} \mathrm{~m}^{2} \mathrm{~K} \mathrm{~kg}^{-1} \mathrm{~s}^{-1}$ from 12 -13 May 2013 (figure 10a-d), whereas there was a burst of upper troposphere PV (figure 11a-d) during its intensification to very severe stage and rapid intensification phases (increased from $1 \times 10^{-6}$ to $8 \times 10^{-6} \mathrm{~m}^{2} \mathrm{~K} \mathrm{~kg}^{-1} \mathrm{~s}^{-1}$ during 9-12 October 2013) for the cyclone Phailin.

\subsection{East-west vertical cross section of potential vorticity $\left(10^{-6} \mathrm{~m}^{2} \mathrm{~K} \mathrm{~kg}^{-1} \mathrm{~s}^{-1}\right)$}

The east-west vertical cross section of PV at 0000 UTC of 12 May 2013 (figure 12a) for cyclone

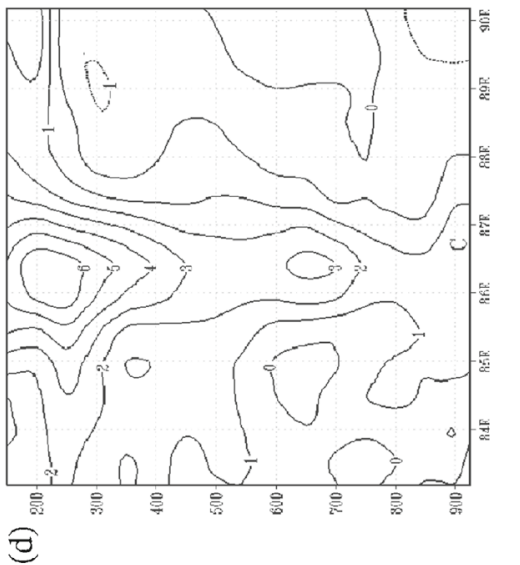

7
0
0
0
0
0
0
0
0
0
0
0
0
0
0
0
0
0
0
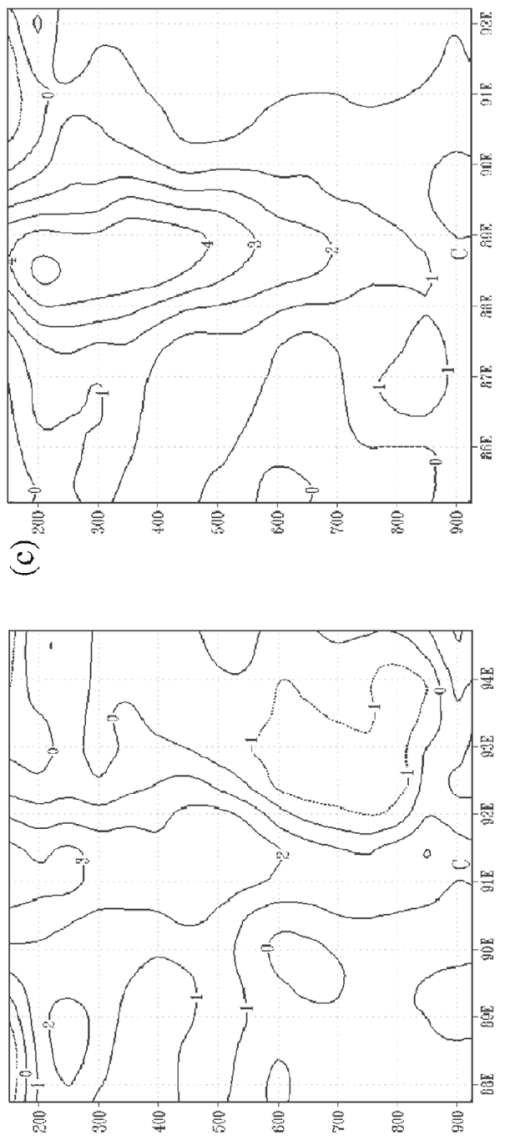

e

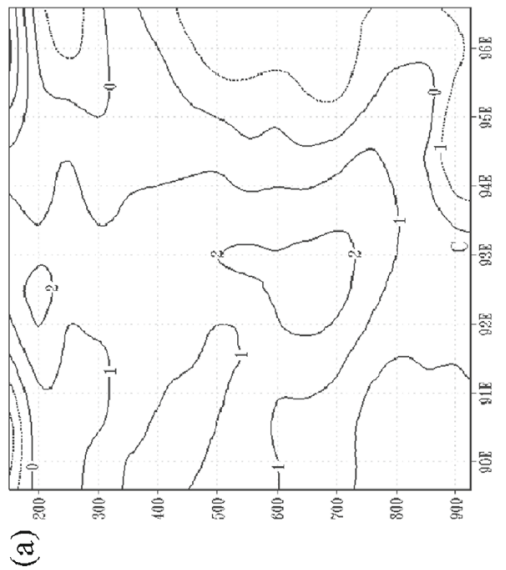

政 


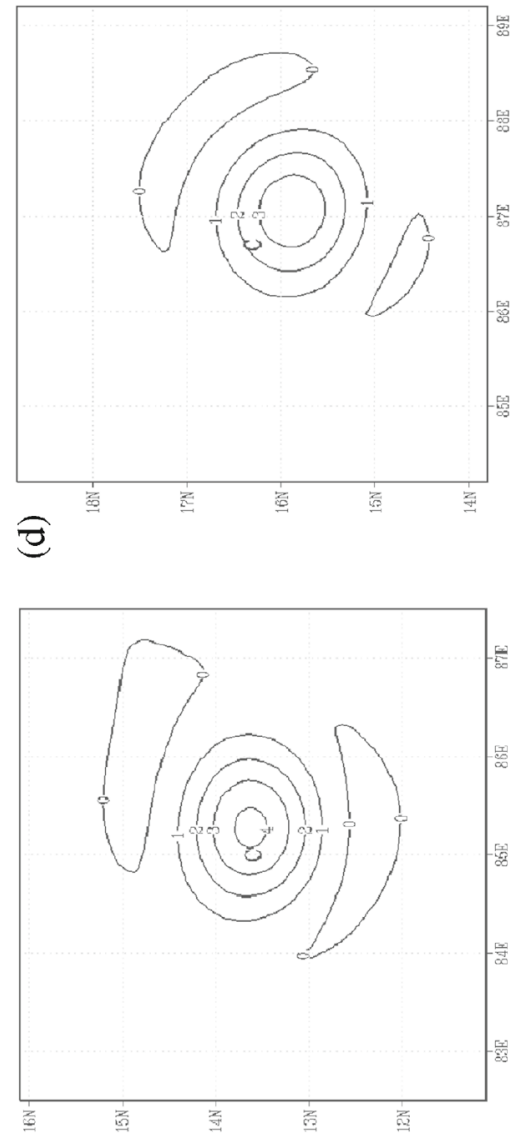

(2)
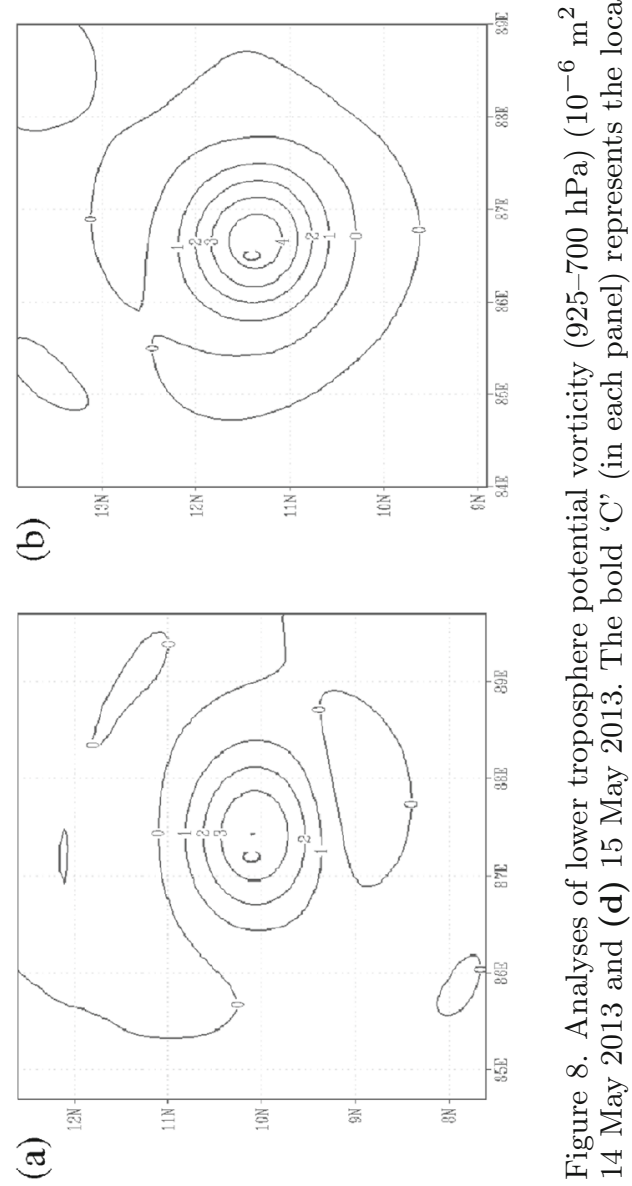

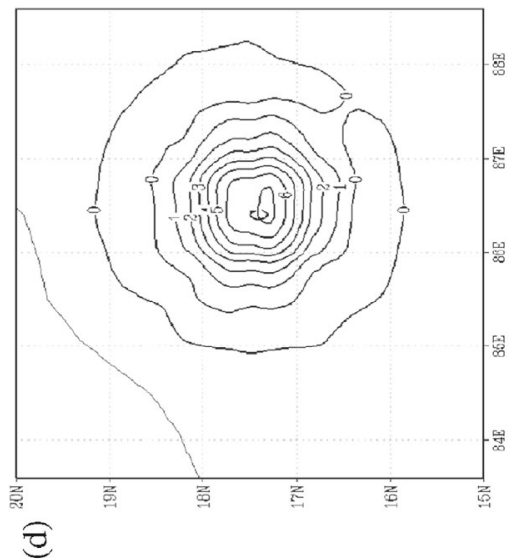

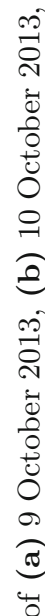
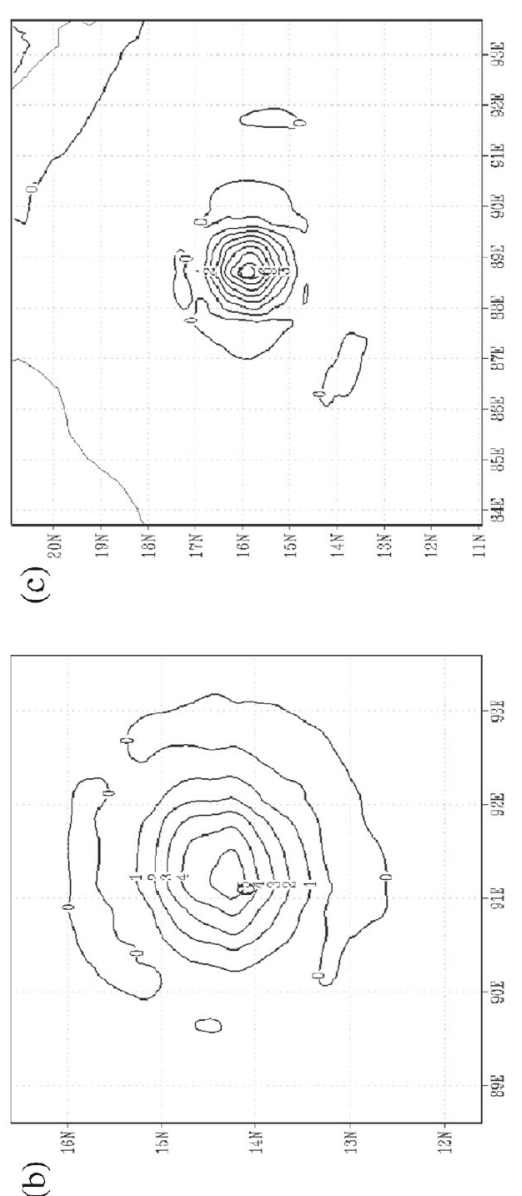

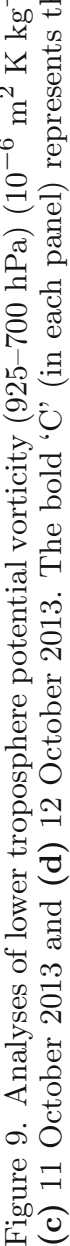



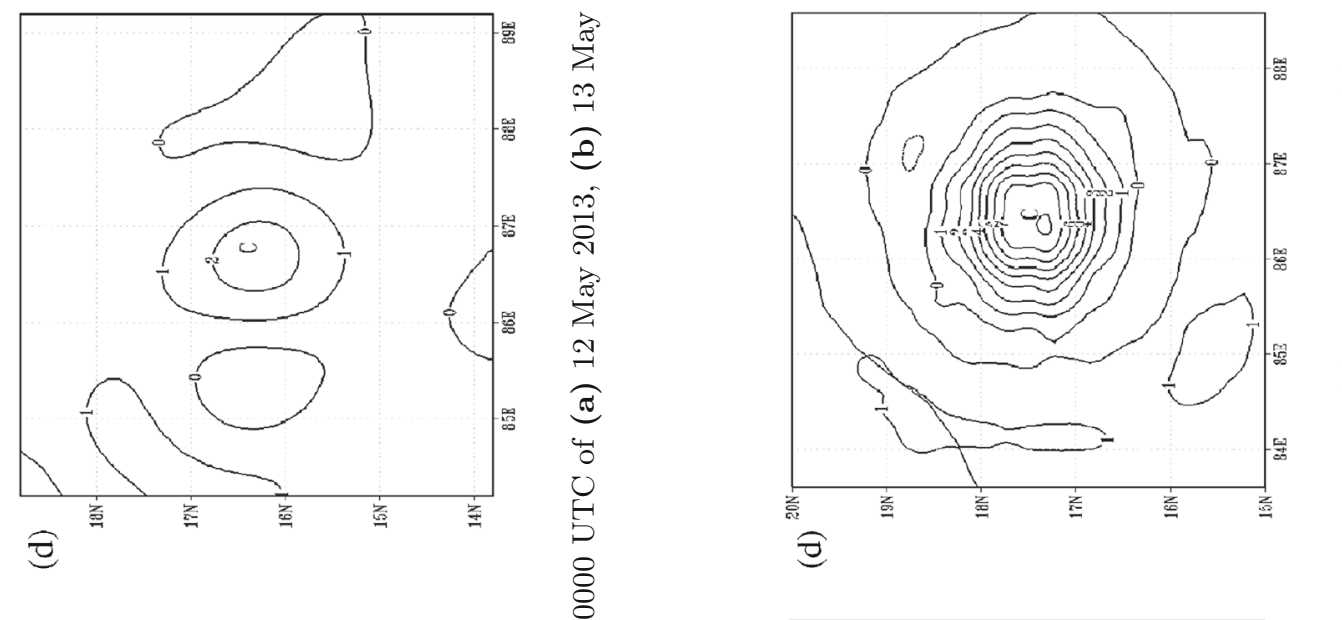

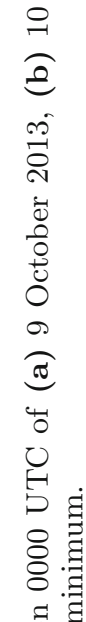
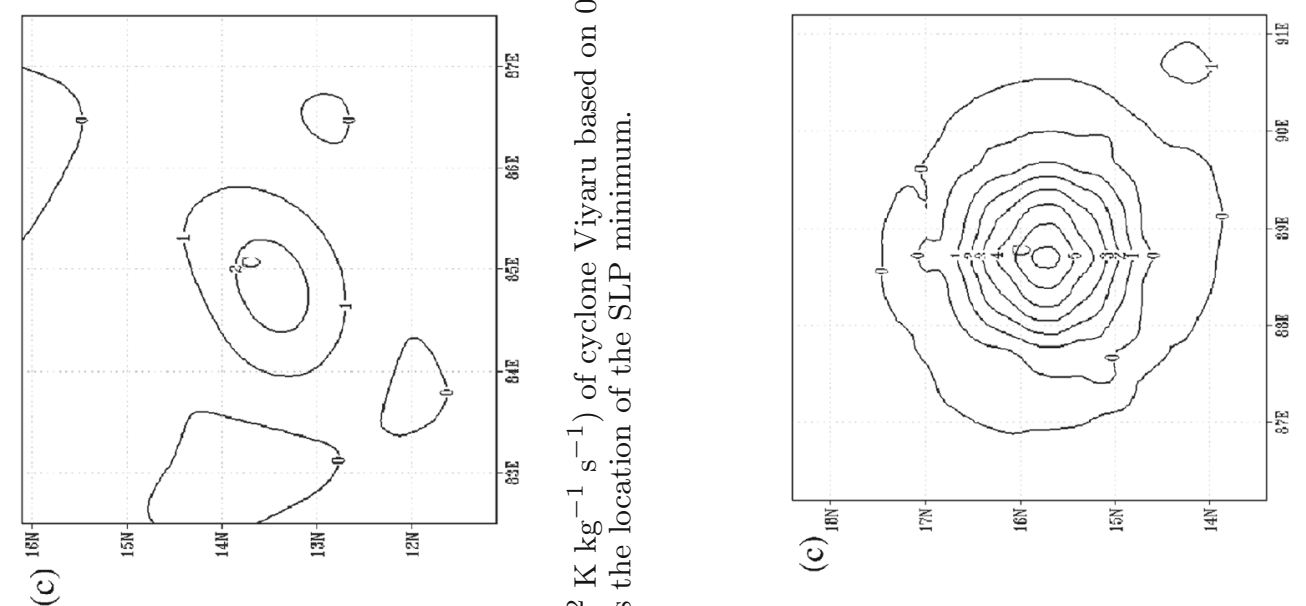

공

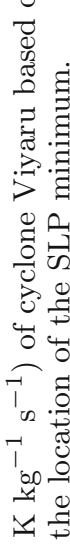

¿्व

10
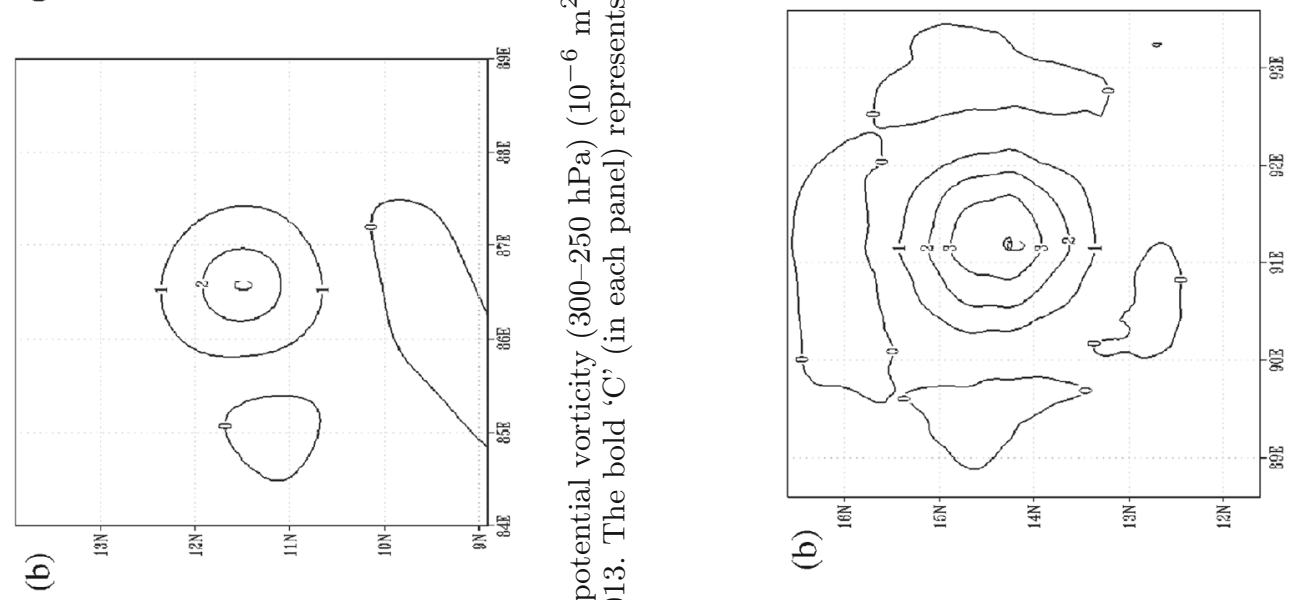

ป

预

के

:

웡

용

in

ᄀ. ํํㄹ

约

दे

100

ब至

$=$

규.

ㄴำ

․․

氙

웅

胥

范

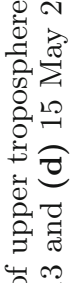

눙

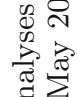

至

잉

总

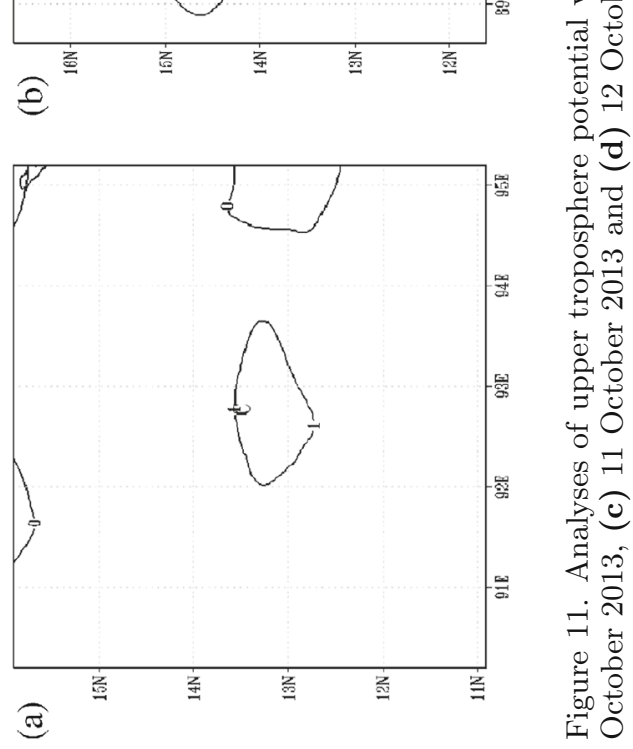



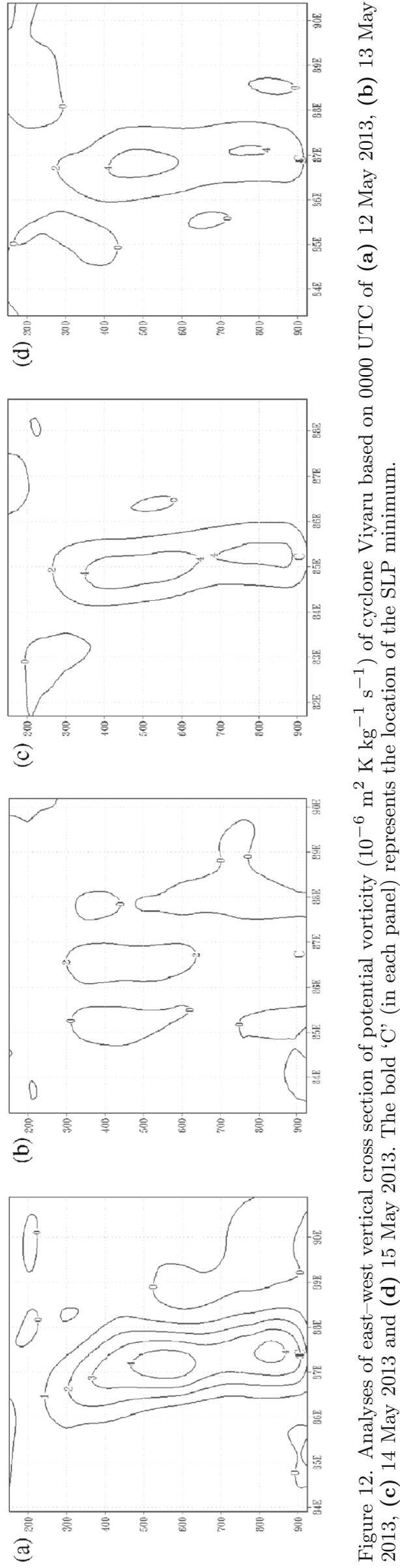

Viyaru shows that PV extended vertically up to $250 \mathrm{hPa}$ with magnitude 1-4 units with maximum of $4 \times 10^{-6} \mathrm{~m}^{2} \mathrm{~K} \mathrm{~kg}^{-1} \mathrm{~s}^{-1}$ up to $500 \mathrm{hPa}$ over the centre of the system and the whole PV profile tilted westward with height. At 0000 UTC of 13 May 2013 (figure 12b) with a value of 2 units vertical PV profile was confined in the middle troposphere only above the system and at 0000 UTC of 14-15 May 2013, the vertical PV profile of magnitude 2 units tilted westward with height (figure $12 \mathrm{c}-\mathrm{d}$ ).

The vertical PV profile from 9-12 October 2013 for cyclone Phailin is shown in figure $13(\mathrm{a}-\mathrm{d})$. The figure shows that the PV increased during its intensification period at all levels from lower troposphere to upper troposphere (above $150 \mathrm{hPa}$ ) from 2-10 units and the whole PV profile was vertical above the system centre. Vertical PV evolution of Phailin had also extended (above $150 \mathrm{hPa}$ ) compared to Viyaru (250 hPa).

\subsection{Middle troposphere (600-400 hPa) relative humidity}

The analysis of the middle troposphere relative humidity (RH) of cyclone Viyaru at 0000 UTC of 12 May 2013 (figure 14a) shows that near the central area of the system the humidity was between $98 \%$ and $90 \%$. At 0000 UTC of 13 May 2013 (figure 14b), the $\mathrm{RH}$ over the area was $100 \%-92 \%$ and was almost symmetrically distributed around the centre. At 0000 UTC of 14 May 2013 (figure 14c), the $\mathrm{RH}$ around the proximity of the system centre was $100 \%$, however, there was penetration of dry air into the storm core (southeast) region of the middle troposphere. At 0000 UTC of 15 May 2013 (figure 14d), the dry air intrusion was very close to the centre system, although the northwest region maintained a high relative humidity. The humidity analyses of cyclone Viyaru show that the humidity in the middle troposphere was significantly lopsided on 3rd (14 May 2013, figure 14c) and the 4th day (15 May 2013, figure 14d) with a clear indication that the system confronted a dry zone on the southeast region and gradually replaced moist air from half of the southeast region in the middle troposphere during its course of development.

The analysis of the middle troposphere $\mathrm{RH}$ of cyclone Phailin at 0000 UTC of 9 October 2013 (figure 15a) shows that there was a dry zone over the north-northwest of the system at the initial deep depression stage. However, the subsequent analyses for 0000 UTC of 10-12 October 2013 shown in figure $15(\mathrm{~b}-\mathrm{d})$ indicate that high relative humidity $(98 \%)$ gradually built up in the middle troposphere and distributed uniformly almost all around the system centre during its development period. 

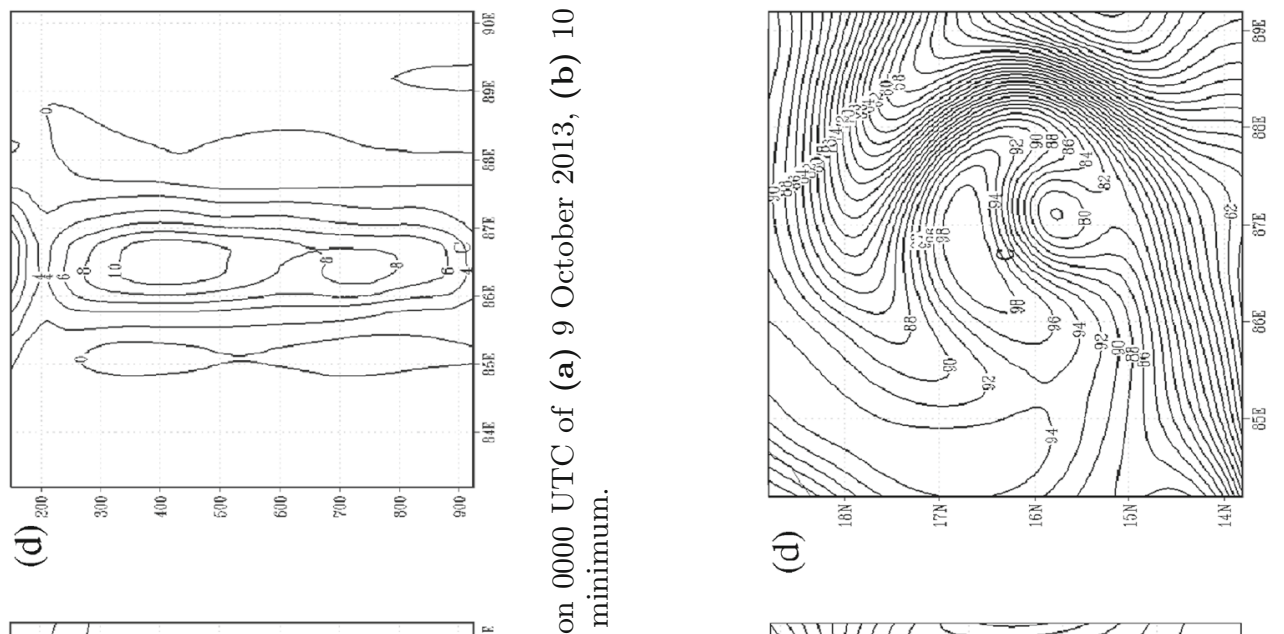

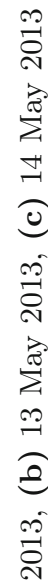
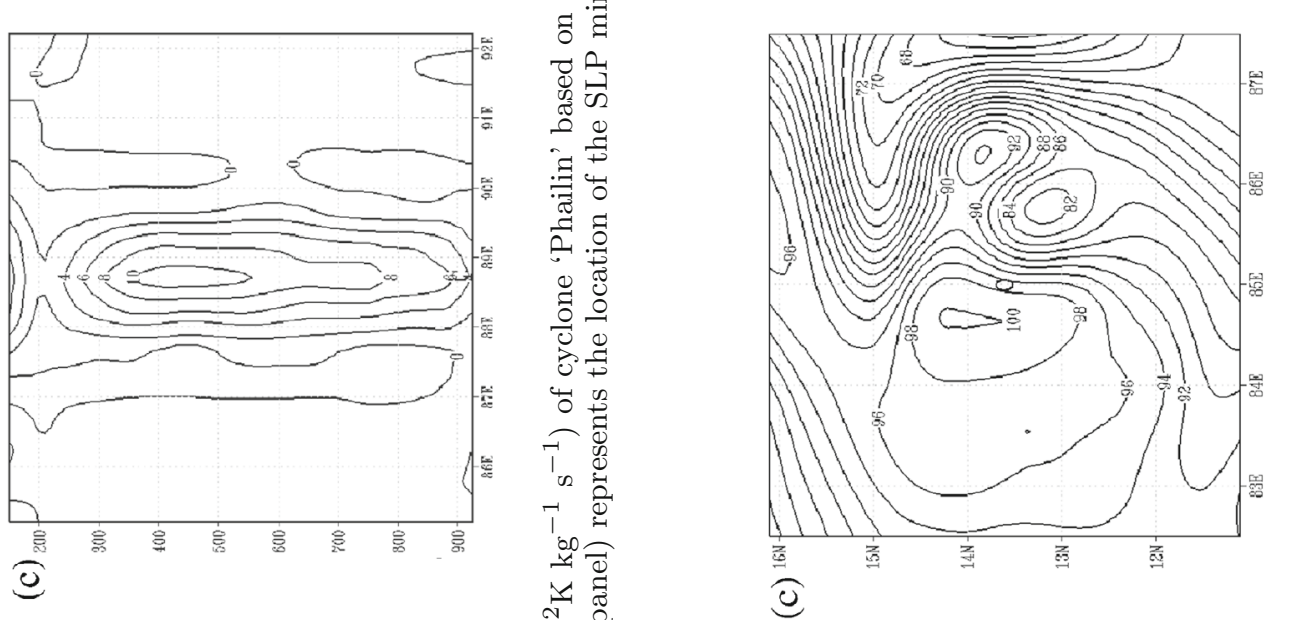

$\stackrel{\Xi}{\Sigma}$

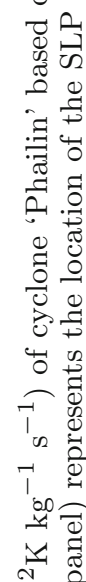

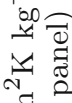

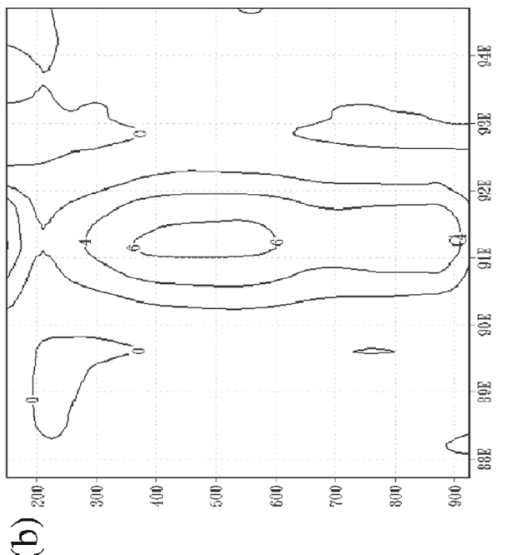

i

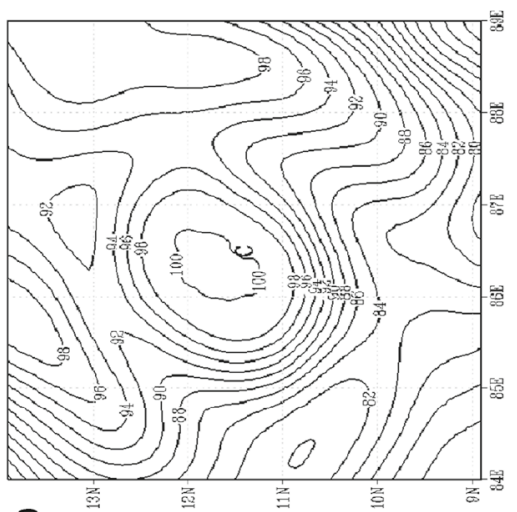

อ

पै
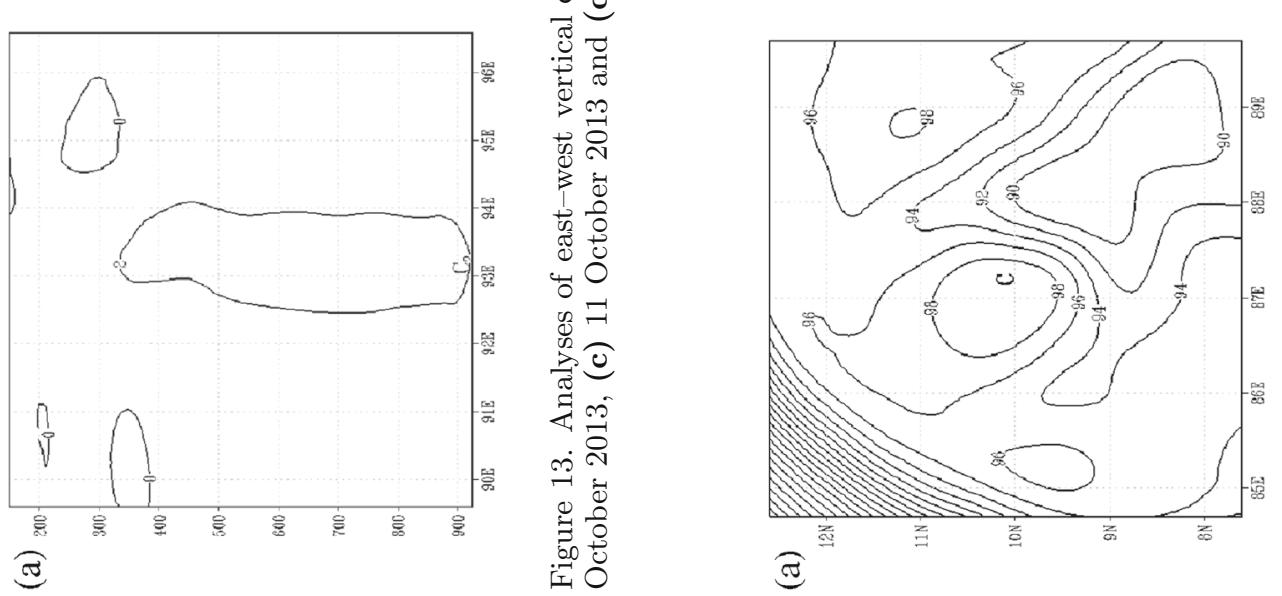

ฮิ

5

$\S$

ฮี

范

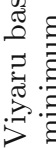

용

S.

虫嵌

:

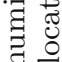

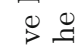

焉

तิ

8

8 ส

త్

.

过

क्ञ

ํํㅇ

$\pm 0$

茐

ठั

苟

晃急

굥

60 

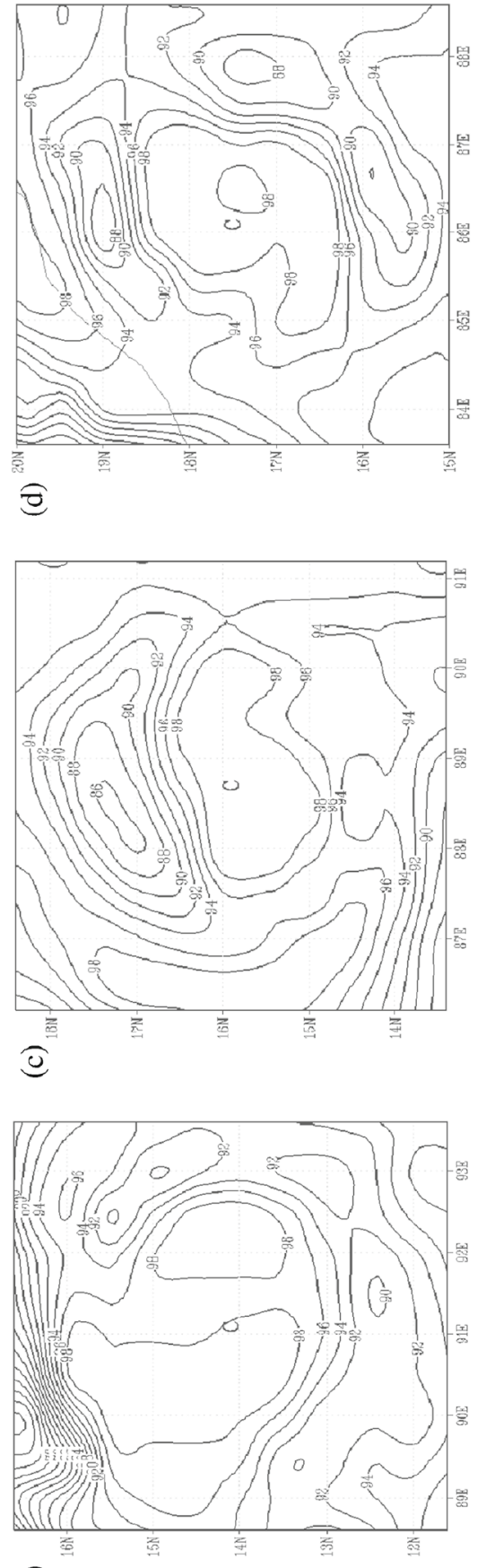

e

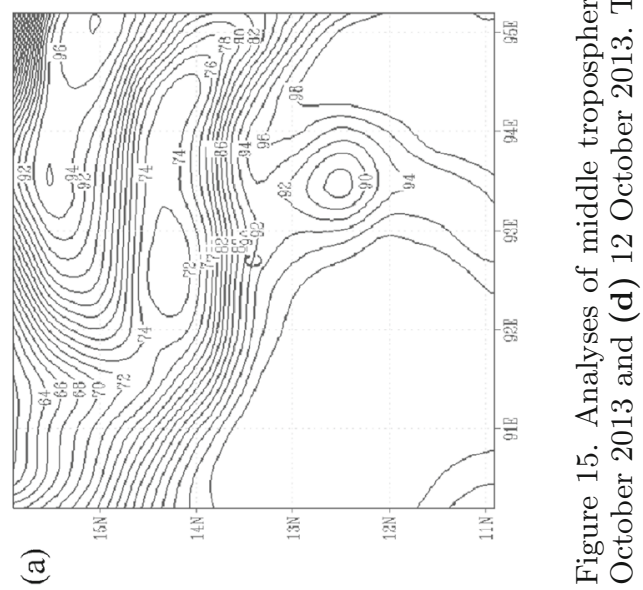

\subsection{Wind shear (mps) analysis (between 850 and $200 \mathrm{hPa}$ levels)}

Figure 16(a-d) shows, barring 13 May, from 0000 UTC of 12-15 May 2013, the area in the proximity of the centre of cyclone Viyaru (marked ' $\mathbf{C}$ '), within $1^{\circ}$ around centre of the system, had strong vertical wind shear $\left(20-25 \mathrm{~ms}^{-1}\right)$ while at 0000 UTC of May 13, it was $15 \mathrm{~ms}^{-1}$. The magnitude of vertical wind shear had also increased from 15 to $25 \mathrm{~ms}^{-1}$ during its northeastward recurvature of movement from 13 to 15 May 2013.

Figure 17(a-d) shows that for the cyclone Phailin, from 0000 UTC of 9-12 October 2013, the wind shear around the centre was $15 \mathrm{~ms}^{-1}$ or lower.

\subsection{Vertical velocity $(\mathrm{Pa} / \mathrm{s})$ at $850 \mathrm{hPa}$}

Vertical velocity analysis at $850 \mathrm{hPa}$ from 0000 UTC of 12-15 May 2013 (figure 18a-d) shows that the area near north of the centre of the cyclone Viyaru (marked ' $C$ ') had a constant value of vertical velocity $(8 \mathrm{~Pa} / \mathrm{s})$ confined within half a degree of cyclone centre. Vertical velocity did not evolve during 12 -14 May 2013 but decreased to $4 \mathrm{~Pa} / \mathrm{s}$ on 15 May 2013 and confined mainly over the northern region.

Vertical velocity analysis at $850 \mathrm{hPa}$ of cyclone Phailin shows that significant evolution of vertical velocity had occurred during the period from 4 to $16 \mathrm{~Pa} / \mathrm{s}$ from $0000 \mathrm{UTC}$ of 9-12 October 2013 (figure 19a-d). Another important feature is that the vertical velocity is gradually distributed uniformly from southwest region in the initial stage to almost all around the system centre during the process of intensification.

\section{Analyses of thermodynamic features}

A number of divergences of various thermodynamic features between cyclones Viyaru and Phailin occurred during their lifecycle. First, the sea level pressure (SLP) and 1000-500 hPa thickness (gpm) gradually changed from concentric to nonconcentric for cyclone Viyaru during its lifecycle (figure $4 \mathrm{a}-\mathrm{d}$ ), whereas the concentric feature was maintained during the lifecycle of cyclone Phailin (figure 5a-d). Second, diabatic heating decreased in the lower troposphere, and was poor along with fluctuations in diabatic heating in the middle and upper troposphere for cyclone Viyaru (figure 6a-d), but there was strong development of diabatic heating in the middle and upper troposphere for cyclone Phailin during its lifecycle (figure $7 \mathrm{a}-\mathrm{d}$ ). Third, the development of potential vorticity (PV) in the lower and upper troposphere was low and 

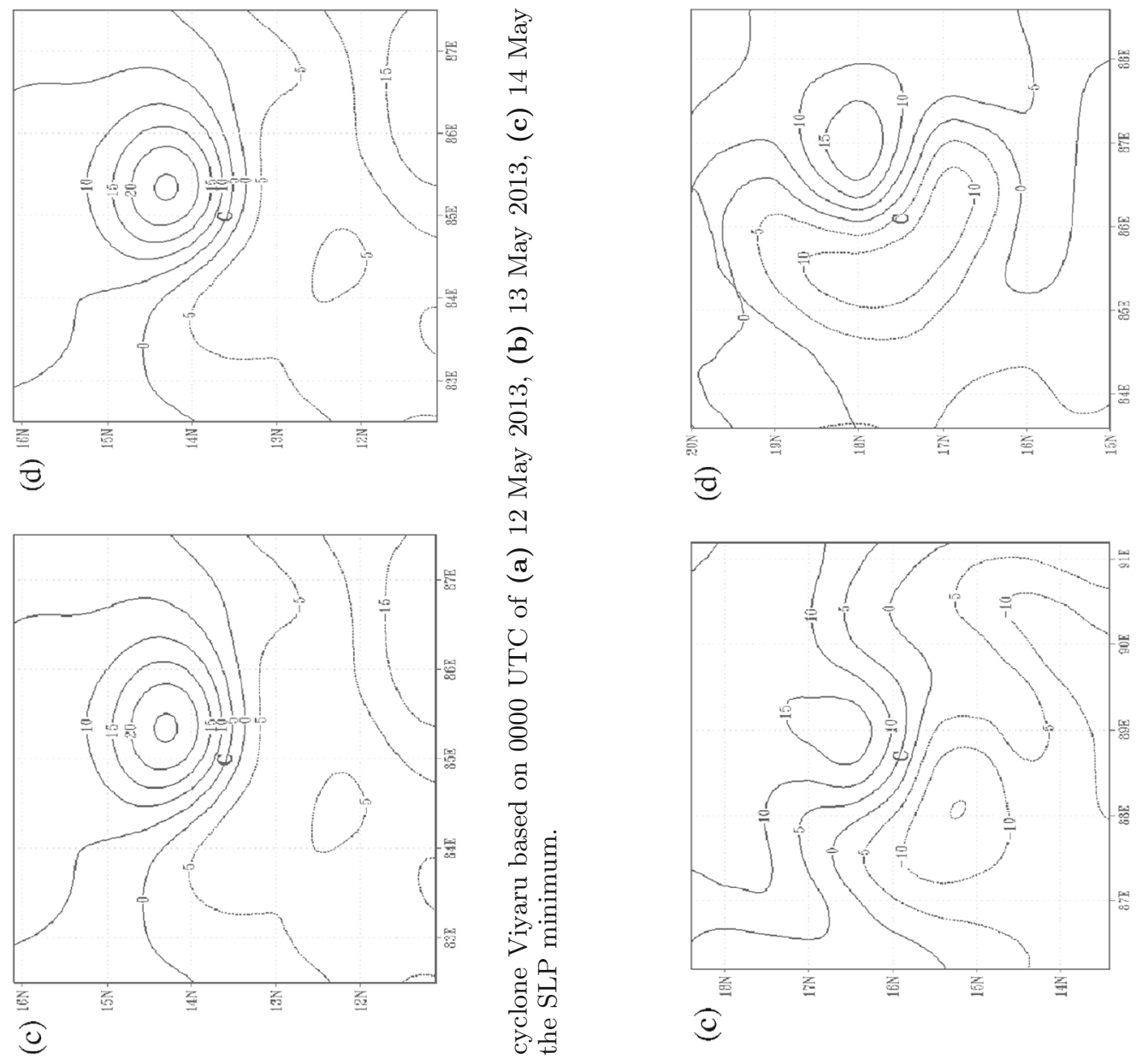

$=$
0
0
0
0
0
0
0
0
0
0
0
0
0
0
0
0
0
0
0
0
0
0
0
0
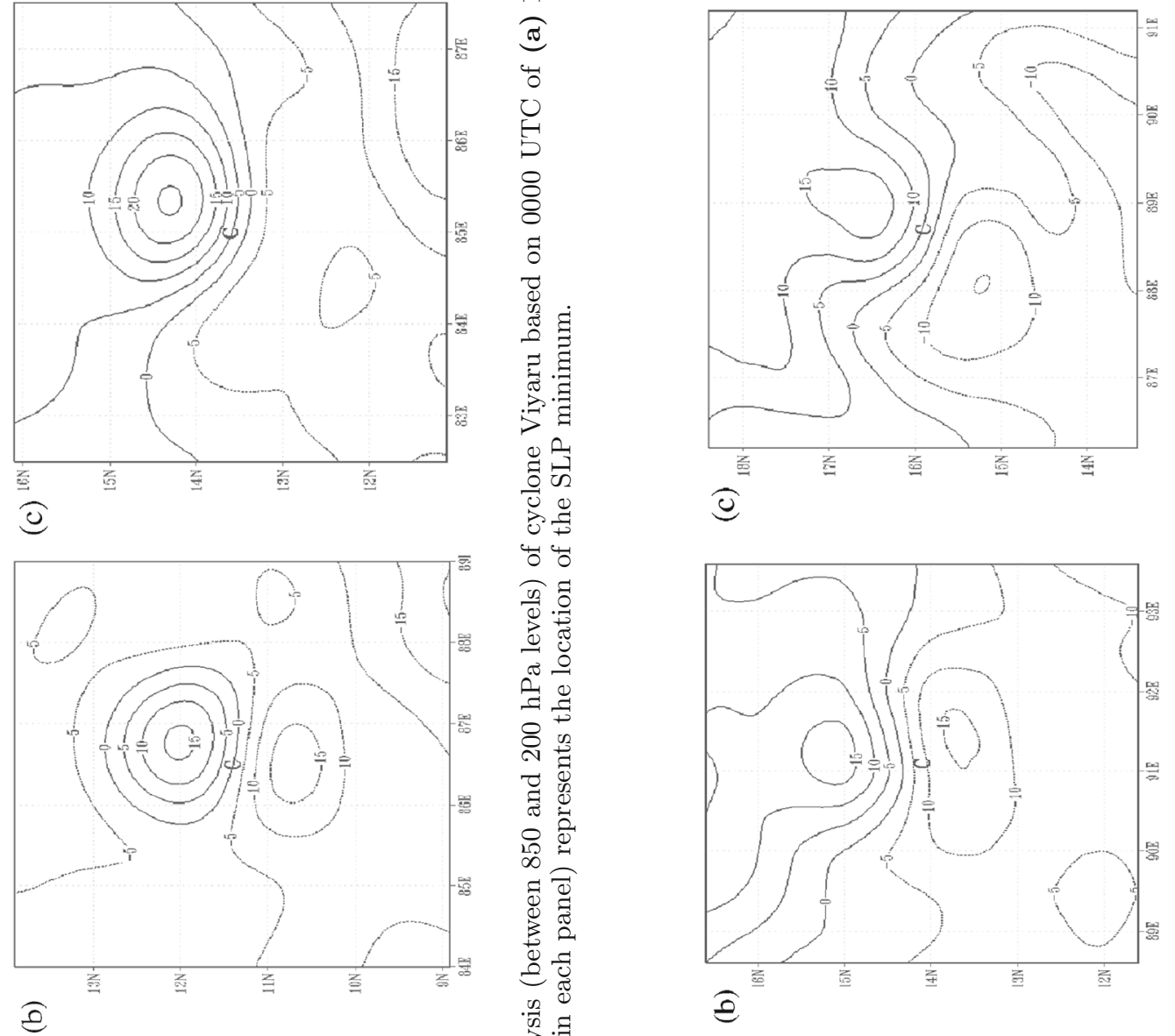

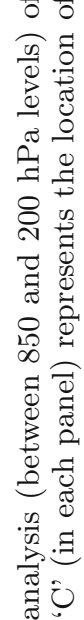

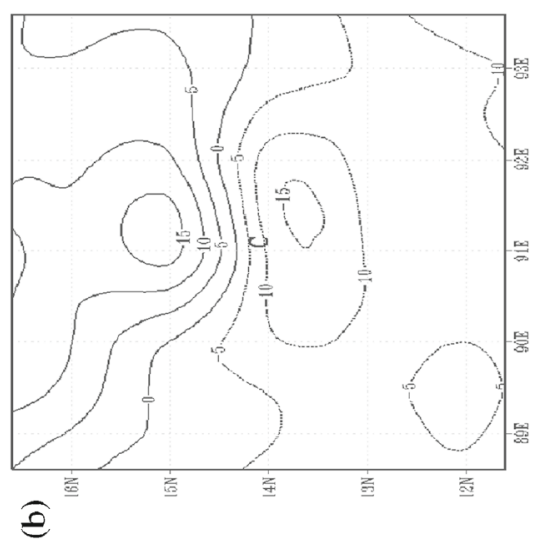

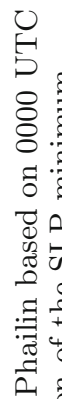

응

ن엉

낭

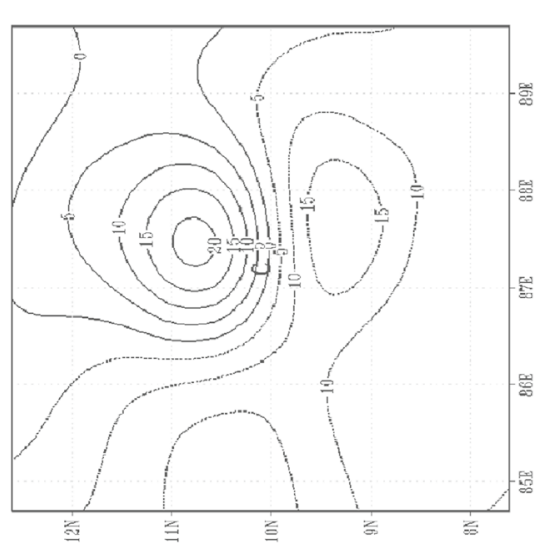

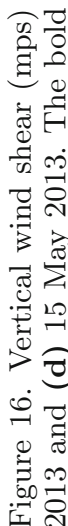

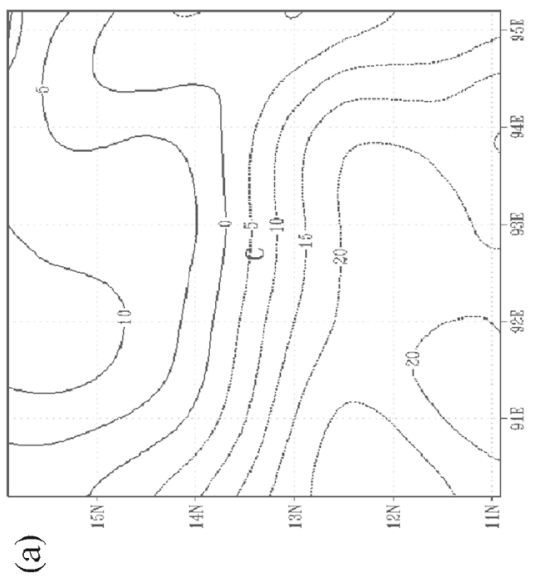

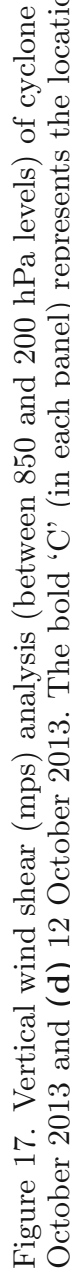



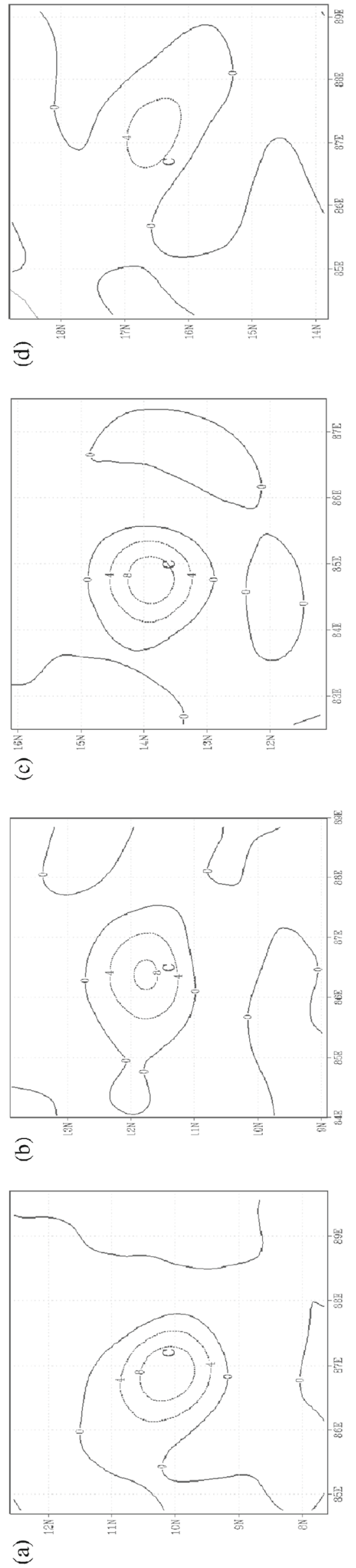
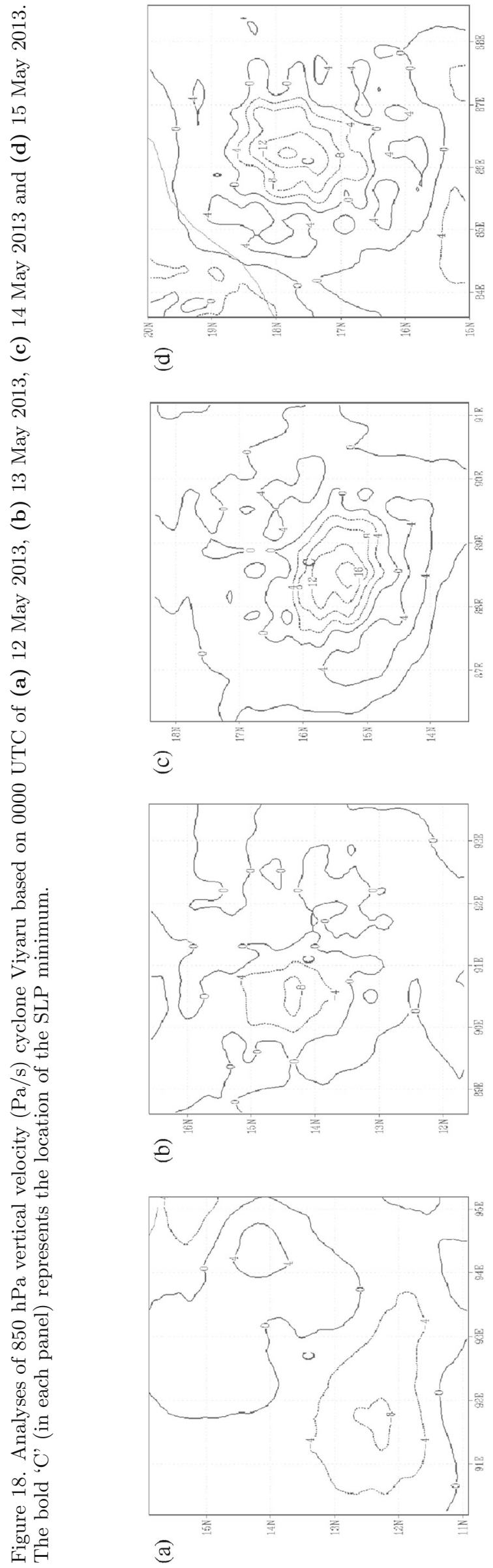

ง

ชิ

뮴

ํㅗำ

항

웅
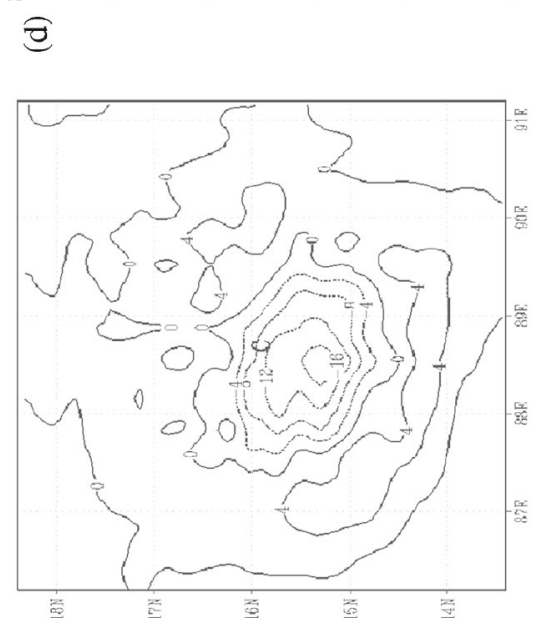

(e)
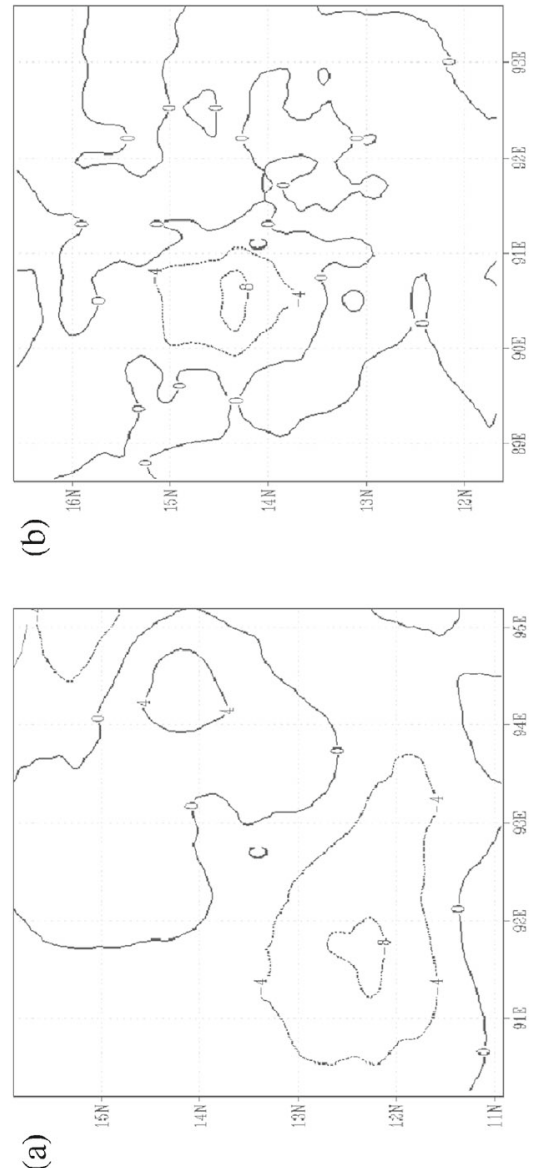

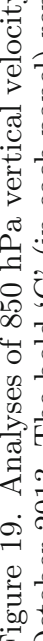


quasi-static for cyclone Viyaru, but there was a burst of PV in both the lower and upper troposphere for cyclone Phailin. Furthermore, the east-west vertical cross sections of the PV profiles (figure $12 \mathrm{a}-\mathrm{d}$ ) and strong vertical wind shear of horizontal wind also indicate a shear-induced vertical tilt (westward) of PV of the cyclone Viyaru and it was vertical and over the system (figure 13a-d) for Phailin. Fourth, there was a penetration of drier air into the core of southeast region and it replaced moist air from almost half of the region of the middle troposphere (figure 14c-d) of cyclone Viyaru, whereas, high relative humidity was distributed uniformly (figure 15b-d) almost all around the centre of Phailin during its lifecycle.

Finally, the structures of SLP, 1000-500 hPa thickness (gpm), PV column, moisture distribution and vertical velocity at $850 \mathrm{hPa}$ indicate that axisymmetrization of structure occurred for cyclone Phailin and the cyclone Viyaru had lack of axisymmetry in its structure.

Deep cumulus convection is essential for the formation and intensification of the tropical cyclone vortex. In the early phases of the TC lifecycle, it is often localized to small horizontal regions in the $\mathrm{TC}$ vortex, and in this sense it can be considered asymmetric with respect to the $\mathrm{TC}$ circulation. It eventually takes the form of an annular ring or a spiral band in the intense phases.

Diabatic heating is generated principally from the latent heat release during atmospheric convection. $\mathrm{PV}$ is generated by diabatic heating. Conzemius Robert and Montgomery (2010) showed that PV structure reflects the diabatic heating structure in a convective region and rapid cyclogenesis is almost entirely a consequence of the diabatically produced PV anomaly (Martin and Otkin 2004). Therefore, the structure of potential vorticity field is used to diagnose the lifecycle of this unusual cyclone.

It has been shown (Gray 1968; Merrill 1988) that the vertical shear of horizontal wind has a negative influence on the intensification of TCs. A common explanation of the effect of vertical wind shear is that the heat of condensation released at upper levels is advected in a different direction relative to the low-level cyclonic circulation and therefore the 'ventilation' of heat away from the circulation inhibits the development of the storm (Gray 1968). DeMaria (1996) showed that the tilt of the upper and lower level PV reduces the convective activity and thus inhibits storm development.

The vertical shear-induced convective asymmetry in the inner core region is considered to be negative to TC intensification (Elsberry et al. 1992). Flatau et al. (1994) demonstrated in their work that the vortex tilting is lowered by the presence of diabatic heating by upward advection of high PV at the core. Frank and Ritchie (2001) attributed the weakening of the TC to the outward mixing of high values of PV by the vertical shear-induced asymmetry in the upper troposphere, resulting in a loss of the warm core at upper levels and weakening of the storm. Dengler and Keyser (2000) found that the penetration of dry air in the mid-levels and regions of boundary-layer convergence reduces the intensity of the storm embedded in uniform environmental flows.

The adiabatic, inviscid mechanism of axisymmetrization (McCalpin 1987; Melander et al. 1987; Sutyrin 1989) has also been proposed to explain vortex intensification. Asymmetric heat sources that evolve over time cause vortex weakening (Nolan et al. 2007) and axisymmetrization of the convective structures are responsible for vortex intensification (Montgomery et al. 2009; Sang et al. 2009).

These ingredients and their consequences are displayed in figures $4-21$. Figures $20(\mathrm{a}-\mathrm{d})$ and $21(\mathrm{a}-$ d) show the Kalpana-I satellite imagery with cloud top temperature (CTT) indicating convection for Viyaru and Phailin respectively. In the early phases of the lifecycle (figure 20a) of Viyaru, the convection was weak $\left(\mathrm{CTT}-50^{\circ} \mathrm{C}\right)$ and localized to southwest regions in the TC vortex. Subsequently, the convection developed $\left(\mathrm{CCT}-80^{\circ} \mathrm{C}\right)$ in the northwest regions, but not in the southeast regions (figure $20 \mathrm{~b}-\mathrm{d}$ ), which is concurrent with the moisture built up in the northwest regions and dry air incursion in the southeast regions (figure 14a-d). In this sense it can be considered asymmetric with respect to the TC circulation, which maintained during its lifecycle. Whereas, in the early phases of the lifecycle (figure 21a) of Phailin, the convection was weak $\left(\mathrm{CTT}-60^{\circ} \mathrm{C}\right)$ and localized to southern regions in the TC vortex, and in this sense it can be considered asymmetric with respect to the TC circulation. It eventually intensified to deep convection $\left(\mathrm{CCT}-80^{\circ} \mathrm{C}\right.$ ) and took the form of a symmetric circular shape (figure $21 b-d$ ) with respect to the $\mathrm{TC}$ circulation in the intense phases. The strong convection occurred in a region of high PV (figure 11b-d) accompanied with high 850-hPa vertical ascent (figure $19 \mathrm{~b}-\mathrm{d}$ ). The intense convective activity was associated with the concurrence of the stronger vertical upward motion at 850 $\mathrm{hPa}$ and high moisture symmetrically distributed (figure $15 \mathrm{~b}-\mathrm{d}$ ) around the centre of Phailin. The vertical distribution of $\mathrm{PV}$ (figure $13 \mathrm{~b}-\mathrm{d}$ ) also shows that there was a concurrence of intensification of Phailin and evolution of PV, and nonintensification of Viyaru associated with quasi-static PV evolution (figure $12 \mathrm{a}-\mathrm{d}$ ). Thus, the principal features such as diabatically-generated PV with core of maximum in the upper troposphere, uniform distribution of high moisture and axisymmetriztion 


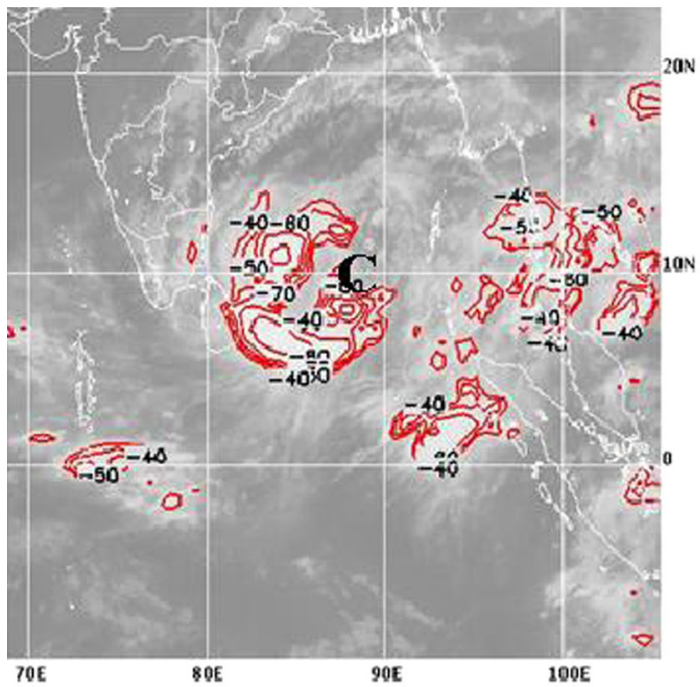

(a)

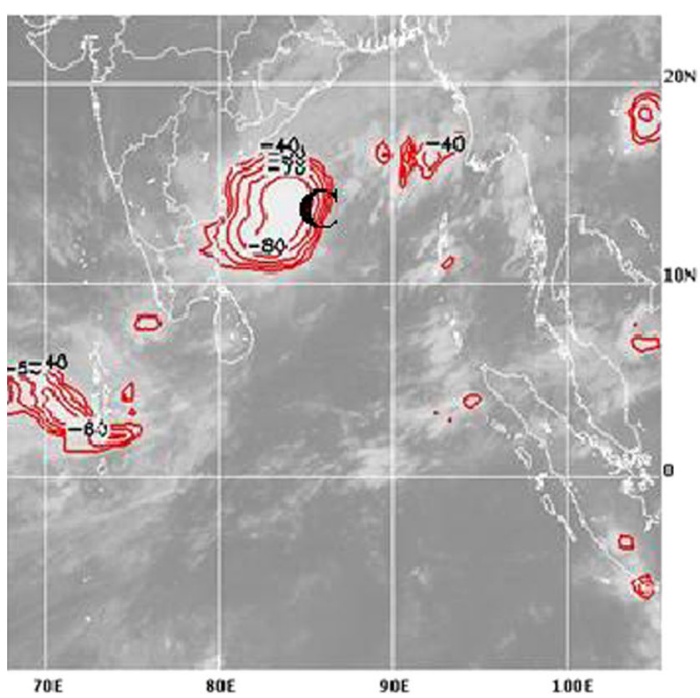

(c)

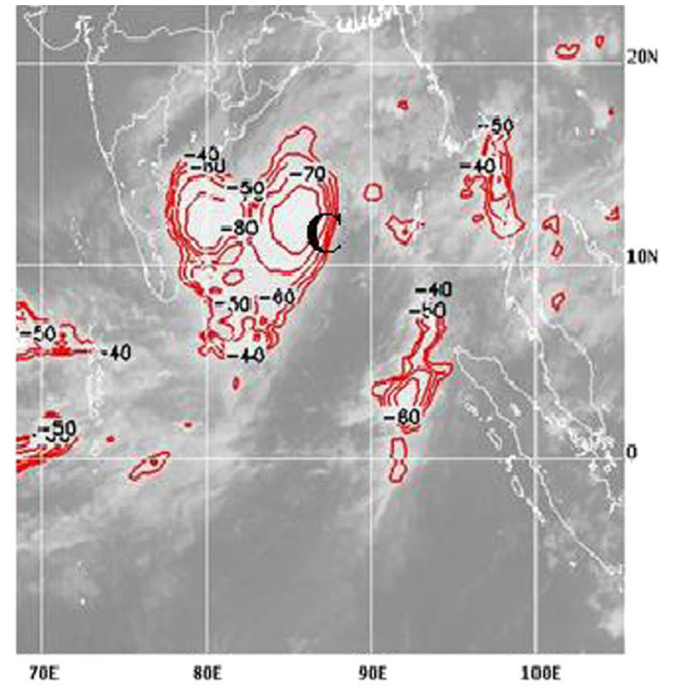

(b)

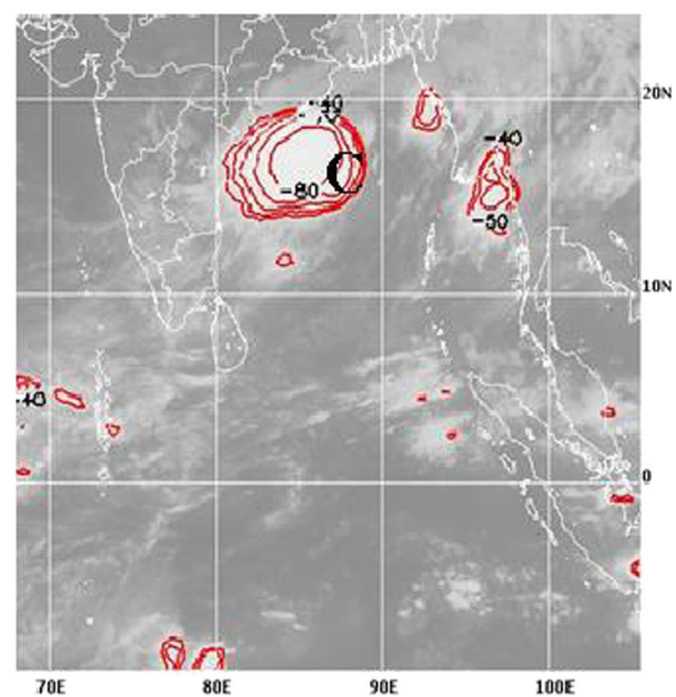

(d)

Figure 20. Kalpana-I satellite imagery with cloud top temperature $\left({ }^{\circ} \mathrm{C}\right.$ ) indicated by solid lines (a) valid at $0000 \mathrm{UTC} 12$ May 2013. The bold 'C' (in each panel) denotes position of SLP minimum of Viyaru. (b) As for (a) except for 0000 UTC 13 May 2013. (c) As for (a) except for 0000 UTC 14 May 2013. (d) As for (a) except for 0000 UTC 15 May 2013.

of convective structure affected the vertical ascent and associated intensification of cyclone Phailin and converse features of thermodynamic parameters are associated with the nonintensification of cyclone Viyaru.

\section{Summary and conclusions}

The dynamics of an unusually nonintensifying cyclone Viyaru and a rapid intensifying cyclone Phailin have been investigated with the aid of potential vorticity diagnostics and various thermodynamic parameters. The cyclone Viyaru travelled about $2150 \mathrm{~km}$ in more than 120 hours over the sea (Bay of Bengal) and having attained the cyclonic storm (CS) intensity did not intensify further. On the contrary, the cyclone Phailin over the Bay of Bengal intensified into very severe cyclonic storm (VSCS) within about 48 hours from its formation as depression.

A number of variances of evolution of thermodynamic features of cyclone Viyaru and Phailin occurred during their lifecycle. First, the sea level pressure (SLP) and 1000-500 hPa thickness (gpm) gradually changes from concentric to nonconcentric for cyclone Viyaru during its lifecycle but the concentric status is maintained during the lifecycle of cyclone Phailin. Second, the poor and fluctuating diabatic heating in the middle and upper troposphere and cooling in the lower troposphere for cyclone Viyaru and strong development of diabatic heating in the middle and upper troposphere for cyclone Phailin during its lifecycle. Third, 


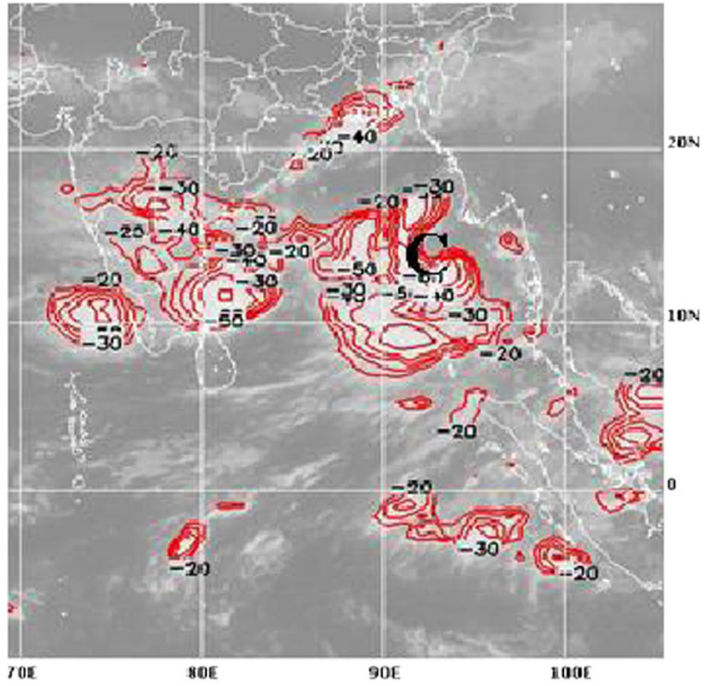

(a)

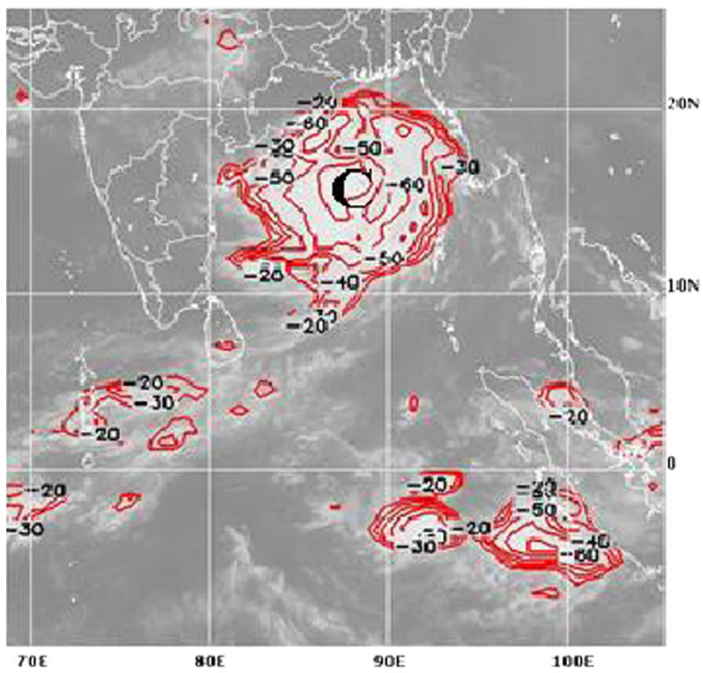

(c)

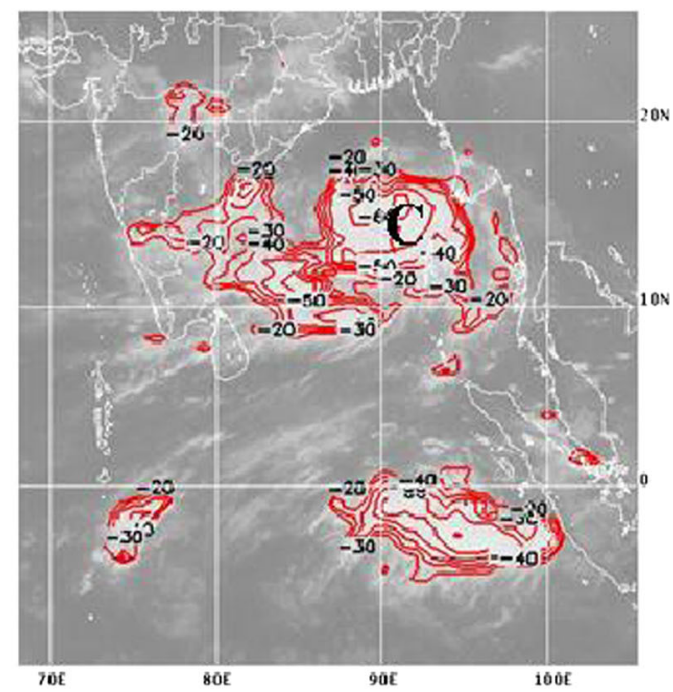

(b)

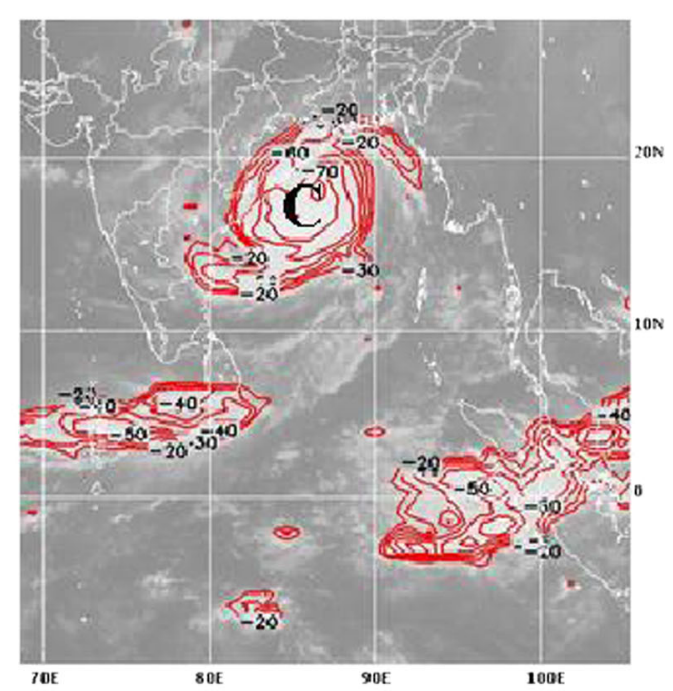

(d)

Figure 21. Kalpana-I satellite imagery with cloud top temperature $\left({ }^{\circ} \mathrm{C}\right)$ indicated by solid lines (a) valid at 0000 UTC 9 October 2013. The bold 'C' (in each panel) denotes position of SLP minimum of Phailin. (b) As for (a) except for 0130 UTC 10 October 2013. (c) As for (a) except for 0200 UTC 11 October 2013. (d) As for (a) except for 0000 UTC 12 October 2013.

the development of potential vorticity (PV) in the lower and upper troposphere was low and quasistatic for cyclone Viyaru, and a burst of PV evolution occurred in both the lower and upper troposphere for cyclone Phailin. The vertical profile of PV tilted due to strong vertical shear of horizontal wind of the cyclone Viyaru and it was vertical and over the system for Phailin. Fourth, there was a penetration of drier air into the core of southeast region and it eventually replaced moist air from almost half of the region of the middle troposphere of cyclone Viyaru, whereas, high moist condition was maintained and distributed uniformly almost all around the centre of Phailin during its lifecycle. Finally, the evolution of structures of SLP, thickness (gpm), PV column, moisture distribution and vertical velocity at $850 \mathrm{hPa}$ shows that axisymmetrization of structure occurred for cyclone Phailin during its lifecycle and the cyclone Viyaru had lack of axisymmetry in its structure. These divergent features conspired to produce the converse characteristic of the two cyclones.

The analysis revealed that the intensification of the cyclone Phailin and nonintensification of cyclone Viyaru occurred through a contrast evolution of convective features. The significant evolution of diabatically-generated lower and upper tropospheric positive PV dominated the rapid intensification of Phailin. The analysis also reveals that the evolution of $\mathrm{PV}$ generated through latent heat release was directly above the surface cyclone and had strengthened due to axisymmeric structure of convective features which in turn affected the vertical ascent and associated surface 
cyclogenesis. On the contrary, quasi-static PV evolution due to poor and fluctuating diabatic heating, penetration of dry air in the middle troposphere, and asymmetric structure limited the intensification of cyclone Viyaru. However, all the above contrast features may vary in terms of their structure and magnitude and may not occur simultaneously for all cases and is likely to be case dependent.

\section{Acknowledgements}

The authors are grateful to the Director General of Meteorology, India Meteorological Department, New Delhi for providing all the facilities to carry out this research work. Authors are grateful to the anonymous reviewers for their valuable comments to improve the quality of the paper.

\section{References}

Anthes R A, Kuo Y H and Gyakum J R 1983 Numerical simulations of a case of explosive cyclogenesis; Mon. Wea. Rev. 111 1174-1188.

Bosart L F, Lai C-C and Rogers E 1995 Incipient explosive marine cyclogenesis: Coastal development; Tellus $\mathbf{4 7}$ $1-29$.

Conzemius Robert J and Montgomery M T 2010 Mesoscale convective vortices in multiscale, idealized simulations: Dependence on background state, interdependency with moist baroclinic cyclones, and comparison with BAMEX Observations; Mon. Wea. Rev. 138 1119-1139.

Dengler K and Keyser D 2000 Intensification of tropical cyclone-like vortices in uniform zonal background flows; Quart. J. Roy. Meteor. Soc. 126 549-568.

DeMaria 1996 The effect of vertical wind shear on tropical cyclone intensity change; J. Atmos. Sci. 53 2076-2088.

DeMaria M, Knaff J A and Bernadette H C 2001 A tropical cyclone genesis parameter for the tropical Atlantic; Wea. Forecasting 16 219-233.

Elsberry R L, Holland G J, Gerrish H, DeMaria M, Guard C P and Emanuel K 1992 Is there any hope for tropical cyclone intensity prediction - a panel discussion; Bull. Am. Meteor. Soc. 73 264-275.

Flatau M, Schubert W H and Stevens D E 1994 The role of baroclinic processes in tropical cyclone motion: The influence of vertical tilt; J. Atmos. Sci. 53 2589-2601.

Frank W M and Ritchie E A 2001 Effects of vertical wind shear on the intensity and structure of numerically simulated hurricanes; Mon. Wea. Rev. 129 2249-2269.

Gray W M 1968 Global view of the origin of tropical disturbances and storms; Mon. Wea. Rev. 96 669-700.

Gray W M 1978 Hurricane and their formation structure and likely role in the tropical circulation; Prepared for the RMS/AMS Conference on Met. over the Tropical Oceans London 21-25 and RMS Conference Volume.

Kaplan J and DeMaria M 2003 Large scale characteristics of rapidly intensifying tropical cyclones in the North Atlantic Ocean; Wea. Forecasting 18 1093-1108.
Kaplan J, DeMaria M and Knaff J A 2009 A revised tropical cyclone rapid intensification index for the Atlantic and eastern North Pacific basins; Wea. Forecasting 25 220-241.

Kotal S D and Roy Bhowmik S K 2013 Large-scale characteristics of rapidly intensifying tropical cyclones over the Bay of Bengal and a rapid intensification (RI) index; Mausam 64 13-24.

Kotal S D, Kundu P K and Roy Bhowmik S K 2009 Analysis of cyclogenesis parameter for developing and nondeveloping low pressure systems over the Indian Sea; Nat. Hazards 50 389-402.

Kotal S D, Tyagi A and Roy Bhowmik S K 2012 Potential vorticity diagnosis of rapid intensification of very severe cyclone Giri (2010) over the Bay of Bengal; Nat. Hazards 60 461-484.

Kuo Y-H and Reed R 1988 Numerical simulation of an explosively deepening cyclone in the eastern Pacific; Mon. Wea. Rev. 116 2081-2105.

Kuo Y-H, Shapiro M A and Donall E G 1991 The interaction between baroclinic and diabatic processes in a numerical simulation of a rapidly intensifying extratropical marine cyclone; Mon. Wea. Rev. 119 368-384.

McCalpin J D 1987 On the adjustment of azimuthally perturbed vortices; J. Geophys. Res. 92 8213-8225.

Melander M V, McWilliams J C and Zabusky N J 1987 Axisymmetrization and vorticity-gradient intensification of an isolated two-dimensional vortex through filamentation; J. Fluid Mech. 178 137-159.

Martin E J and Otikin A J 2004 The rapid growth and decay of an extratropical cyclone over the central Pacific Ocean; Wea. Forecasting $19358-376$.

Merrill R T 1988 Environmental influences on hurricane intensification; J. Atmos. Sci. 45 1678-1687.

McBride J L and Zehr R M 1981 Observational analysis of tropical cyclone formation. Part 2: Comparison of developing versus non-developing system; J. Atmos. Sci. 38 1132-1152.

Montgomery M T, Sang N V, Smith R K and Persing J 2009 Do tropical cyclones intensify by WISHE? Quart. J. Meteor. Soc. 135 1697-1714.

Nolan David S, Moon Yumin and Stern Daniel P 2007 Tropical cyclone intensification from asymmetric convection: Energetics and efficiency; J. Atmos. Sci. 64 3377-3405.

Roy Bhowmik S K 2003 An evaluation of cyclone genesis parameter over the Bay of Bengal using model analysis; Mausam 54 351-358.

Sanders F 1986 Explosive cyclogenesis in the west-central North Atlantic Ocean 1981-1984. Part I: Composite structure and mean behavior; Mon. Wea. Rev. 114 1781-1794.

Sanders F and Gyakum J R 1980 Synoptic-dynamic climatology of the Bomb; Mon. Wea. Rev. 108 15891606.

Sang N V, Smith R K and Montgomery M T 2009 Tropical cyclone intensification and predictability in three dimensions; Quart. J. Meteor. Soc. 134 563-582.

Sutyrin G G 1989 Azimuthal waves and symmetrization of an intense vortex; Sov. Phys. Dokl. 34 104-106.

Whitaker J S, Uccellini L W and Brill K F 1988 A modelbased diagnostic study of the rapid development phase of the Presidents' Day cyclone; Mon. Wea. Rev. 116 2327-2365. 